\title{
Regulation of Vascular Tone, Molecular Mechanisms
}

\author{
R. Clinton Webb and David F. Bohr
}

$\mathbf{V}^{\mathrm{s}}$ ASCULAR tone, a state of maintained contraction of the smooth muscle in the vessel wall, is the process by which the blood vessel carries out its physiologic functions, its pharmacologic responses, and its pathologic changes. Current research directed at an understanding of the molecular mechanisms that regulate vascular tone is progressing at a rapid rate. The state of this art was surveyed in 1980 by the American Physiological Society's 686-page Physiology Handbook, Section 2, Volume II, "Vascular Smooth Muscle."

The current review should satisfy those who have in mind a less extensive compilation of information. It also describes new pieces of the puzzle that have been found since the Handbook went to press over a year ago.

In the broadest sense, pieces of this puzzle are sought to complete two quite different pictures, both depicting the affairs of calcium. The first deals with the role of calcium in the regulation of the contractile proteins; the second with the function of cell membranes in the regulation of myoplasmic calcium concentration.

\section{STRUCTURE AND CHEMISTRY OF CONTRACTILE ELEMENTS}

Over the past decade, a comfortable concensus has evolved about the structural components involved in the contractile process of smooth muscle. ${ }^{1,2}$ The components include three types of filaments plus dense bodies and attachment plaques. When the isolated smooth muscle is observed to contract, ${ }^{3}$ small closely spaced blebs are formed on the cell surface, interspersed with small undistorted regions. With relaxation, the blebs disappear. It is assumed that the undistorted regions are attachment sites for the forcegenerating units to the plasmalemma. The ultrastructure demonstrates dense areas on the plasmalemma, which are probably attachment sites of the filaments. These are the "attachment plaques." Somewhat similar structures called "dense bodies" are dispersed throughout the sarcoplasm and are believed by some to be intracellular attachments for contractile filaments. Throughout the sarcoplasm, there is a network of $10-\mathrm{nm}$ (intermediate) filaments that are believed to play a role in the structural or "skele- tal" integrity of the cell. These are comprised of a 55,000 dalton protein, skeletin. The actual contractile apparatus of vascular smooth muscle is comprised of thick $(14.5 \mathrm{~mm})$ and thin $(6.4$ $\mathrm{mm}$ ) filaments. Strong circumstantial evidence supports the hypothesis that force is generated in a manner similar to the now classical sliding filament model of striated muscle. A schematic model of the molecular relationship between the thick and thin filaments is shown in Fig. $1{ }^{4}$ In this model, neither filament changes length, but through a force generated between the two types of filaments, they slide by one another in such a fashion that the length of the cell tends to shorten.

There are two striking differences between the geometric arrangements of filaments in smooth muscle as compared to those of striated muscle. In the first place, the ratio of the number of thin to thick filaments is approximately $15: 1$ in smooth muscle, in comparison to $2: 1$ in striated muscle. The second difference is in the less well regimented arrangement of the thick and thin filaments in smooth muscle. When the muscle is relaxed, the filaments appear to lie parallel to the long axis of the cell. However, when the cell shortens, their arrangement tends to become progressively more oblique. When the cell has shortened maximally, the angle between the axis of the cell and the filaments may be as great as $25-40^{\circ} .5$ The chemistry of the contractile proteins to be dealt with in the following paragraphs has been extensively reviewed in the current literature. ${ }^{1,4,6,7}$

\section{Myosin}

Each thick filament is comprised of upwards of 200 myosin molecules. These are fibrous

\footnotetext{
From the Department of Physiology, University of Michigan. Ann Arbor. Mich.

Supported in part by the National Institutes of Health Grant HL-18575, by the Michigan Heart Association, and by the Michigan Memorial Phoenix Project.

Reprint requests should be addressed to $R$. Clinton Webb. M.D.. Department of Physiology. University of Michigan. Ann Arbor, Mich. 48109.

(C) 1981 by Grune \& Stratton, Inc.

0033-0620/81/2403-0002\$05.00/0
} 


\section{ACTOMYOSIN}

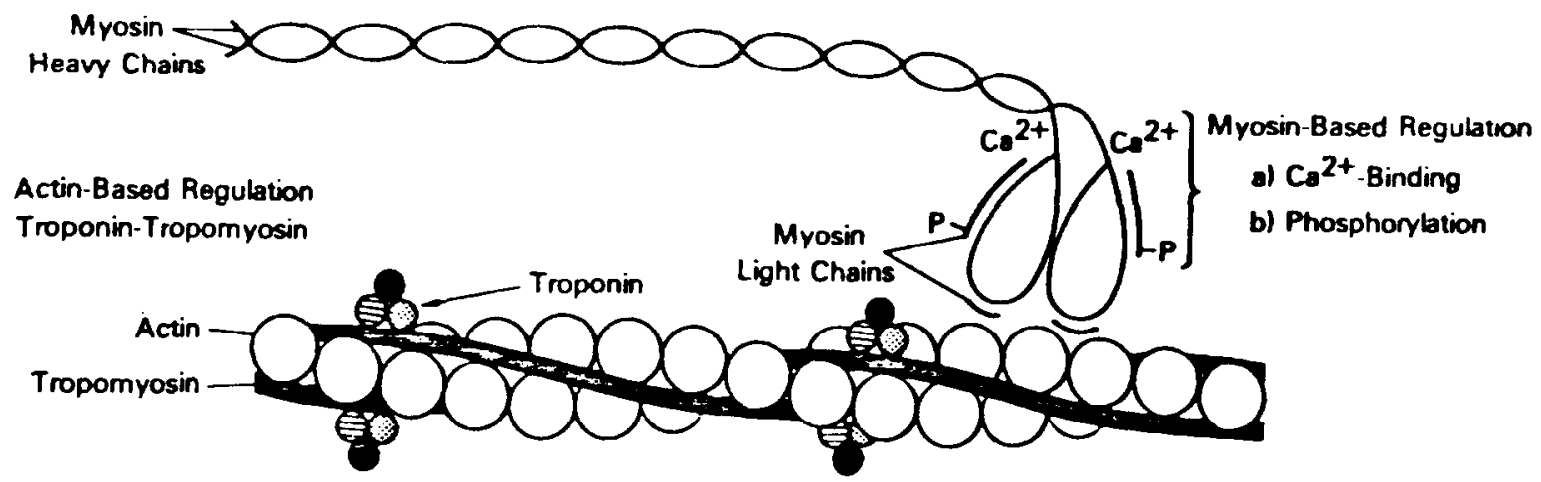

Fig. 1. Diagram of relationship between myosin and actin. The diagram shows components of three regulatory systems for actomyosin ATPase activation. (1) The thin filament regulatory system in which three troponin molecules plus tropomyosin act cooperatively in response to an increase in free ionized calcium to permit the activation of the myosin ATPase of the globular portion of the myosin molecule by actin. (2) Actin activation of myosin ATPase by a direct binding of calcium to myosin. (3) Phosphorylation of the 20,000 dalton myosin light chain, thereby disinhibiting the actomyosin ATPase. Not shown in this diagram is a second thin filament regulating system that involves leiotonin molecules, ${ }^{7}$ which are bound to actin. (Reproduced by permission of Annual Review of Biochemistry. ${ }^{4}$ )

structures with globular ends. With appropriate enzymatic treatment, the myosin molecule may be separated into two parts, heavy and light meromyosin. Light meromysin is a fibrous protein that lines up in a sheath with other similar molecules to form the thick filament. Heavy meromyosin makes up the bridge that protrudes from the thick filament. In its functional operation, the myosin molecule behaves as if there were a flexible hinge between these two components. The fibrous portion of the molecule transmits forces generated by the heavy meromyosin. The heavy meromyosin may be further fractionated into a fibrous S-2 segment and a globular S-1 segment (Fig. 1). The latter is the operational site of the molecule. It contains the attachment site for actin and the enzymatic site that hydrolyzes adenosine triphosphate (ATP) to release free energy for contraction. Two "myosin light chains," which are components of the globular S-1 segment, are involved in the function of this molecule. Phosphorylation of the 20,000 dalton light chain, as will be discussed later, plays an important role in the initiation of the contractile process; the function of the other 17,000 dalton light chain is not as clearly defined. There are distinct differences in chemistry and function between the myosin light chains of vascular smooth muscle and those of skeletal muscle.
Actin

Actin, which is the major component of the thin filament, is present in all mammalian cells. There is little difference in the chemical composition of actin from different sources. Fibrous actin, which comprises the thin filament, is composed of two strands of 42,000 dalton globular actin molecules. Two functional roles of actin in the contractile process are: (1) transmission of force delivered by the movement of the bridge of the myosin molecule, and (2) activation of the myosin ATPase to release free energy for contraction.

\section{Tropomyosin}

Tropomyosin, as actin, is a fairly uniform molecule in all types of muscle. It has a molecular weight of approximately 70,000 daltons and is an alpha helix closely attached to the actin molecule in the thin filament. Furthermore, the ratio of tropomyosin to actin molecules (approximately 1:3) is similar in all types of muscle. The major difference between striated and smooth muscle with regard to their thin filaments is that in striated muscle these contain readily extractable troponin molecules, whereas that of smooth muscle does not. There is controversial evidence that some regulatory system, such as leitonin, may be associated with actin and tropomyosin of smooth muscle. 
In skeletal muscle, the troponin-tropomyosin system is the major protein regulator of contractile activity. In the resting muscle, it inhibits the activation of myosin ATPase by actin. This inhibition is nullified by the presence of an adequate concentration of free ionized calcium in the myoplasm. It now appears that there is no such inhibitory action of tropomyosin in smooth muscle. Instead, tropomyosin seems to amplify the actin-activated ATPase activity of smooth muscle. $^{8}$

\section{Relations of Myosin and Actin}

The hydrolysis of ATP is the source of energy release for muscle contraction. In the intact muscle, this ATPase activity is effected by the S-1 segment of the myosin molecule, which has been activated by actin. It is the myosin molecule, not the actin, that determines the velocity of the ATPase activity and hence the energy release. Barany ${ }^{9}$ demonstrated that, in different muscles, the maximal shortening velocity is directly correlated with the actin-activated myosin ATPase activity of that muscle. This shortening velocity of vascular smooth muscle is approximately $1 \%$ as fast as that of fast skeletal muscle, reflecting a marked difference in the velocity of ATPase activities of these two muscles. On the other hand, force-generating ability of arterial muscle is, if anything, greater than that of skeletal muscle. ${ }^{10}$ Whereas the speed of contraction is believed to be a function of the actomyosin ATPase activity, and hence of the cycling rate of the myosin bridge, the force of contraction is considered to be a function of the number of simultaneously active force-generating relationships between the myosin bridge and the thin filament. Both structural and biochemical studies have indicated that there is a much higher ratio of thin filaments to thick filaments in vascular smooth muscle than in skeletal muscle (15:1 for vascular smooth muscle and 2:1 for skeletal muscle). Although there is less myosin in smooth than in skeletal muscle, this marked difference in ratio may result in a physical arrangement in which a greater number of force-generating sites may be active at one time. Even among smooth muscles, there are differences in the ratio of actin to myosin on a weight basis, " whereas the average weight ratio of actin to myosin extracted from various arterial muscles is 2.6 , this ratio for nonarterial muscle is 1.5 .

The failure of this review to describe the basic mechanism by which the relationship between myosin and actin results in force generation does not reflect a negligence on the part of the reviewers. It merely reflects the fact that this information is not available in current literature.

\section{Regulation of Contractile Protein Activity}

When the membrane structures that govern calcium concentration in the myoplasm are destroyed by glycerol extraction, the contractile activity becomes immediately dependent on the presence of calcium in the environment of the muscle. In 1964, Filo et al. ${ }^{12}$ observed that glycerol-extracted skeletal muscle and vascular smooth muscle had identical calcium dependencies (see Fig. 2). At that time, the similarity of these calcium response curves was interpreted as indicating that the molecular mechanisms by which calcium-altered contractile protein activity was the same in these two types of muscle. Evidence developed in the intervening time has shown that this conclusion was clearly in error. It is now evident that the molecular mechanisms by which calcium alters the contractile activity vary greatly in different types of muscle. Yet, it is still of interest that, in spite of a great variation in the evolution of calcium regulatory processes, ${ }^{13}$ the same calcium sensitivity (concentration-response curve) is maintained throughout.

The mechanisms that regulate contractile protein activity are usually assessed by monitoring the effect of calcium on the ATPase activity or on superprecipitation of actomyosin. These regulatory mechanisms are shown schematically in Fig. 3. They are broadly classified as those residing in the thin filament (actin-linked) or in the thick filament (myosin-linked) and will be described in some detail in the following parts of this review. Ebashi and Kodama ${ }^{14}$ first demonstrated a thin filament regulating system in mammalian skeletal muscle around 1965, and 5 yr later, Kendrick-Jones et al. ${ }^{15}$ found that contraction of the molluscan muscle was regulated by a thick filament system. It was known that crude or native actomyosin from either skeletal or molluscan muscle was inactive in the absence of calcium but could be activated by the addition of calcium. Ebashi observed that in the 


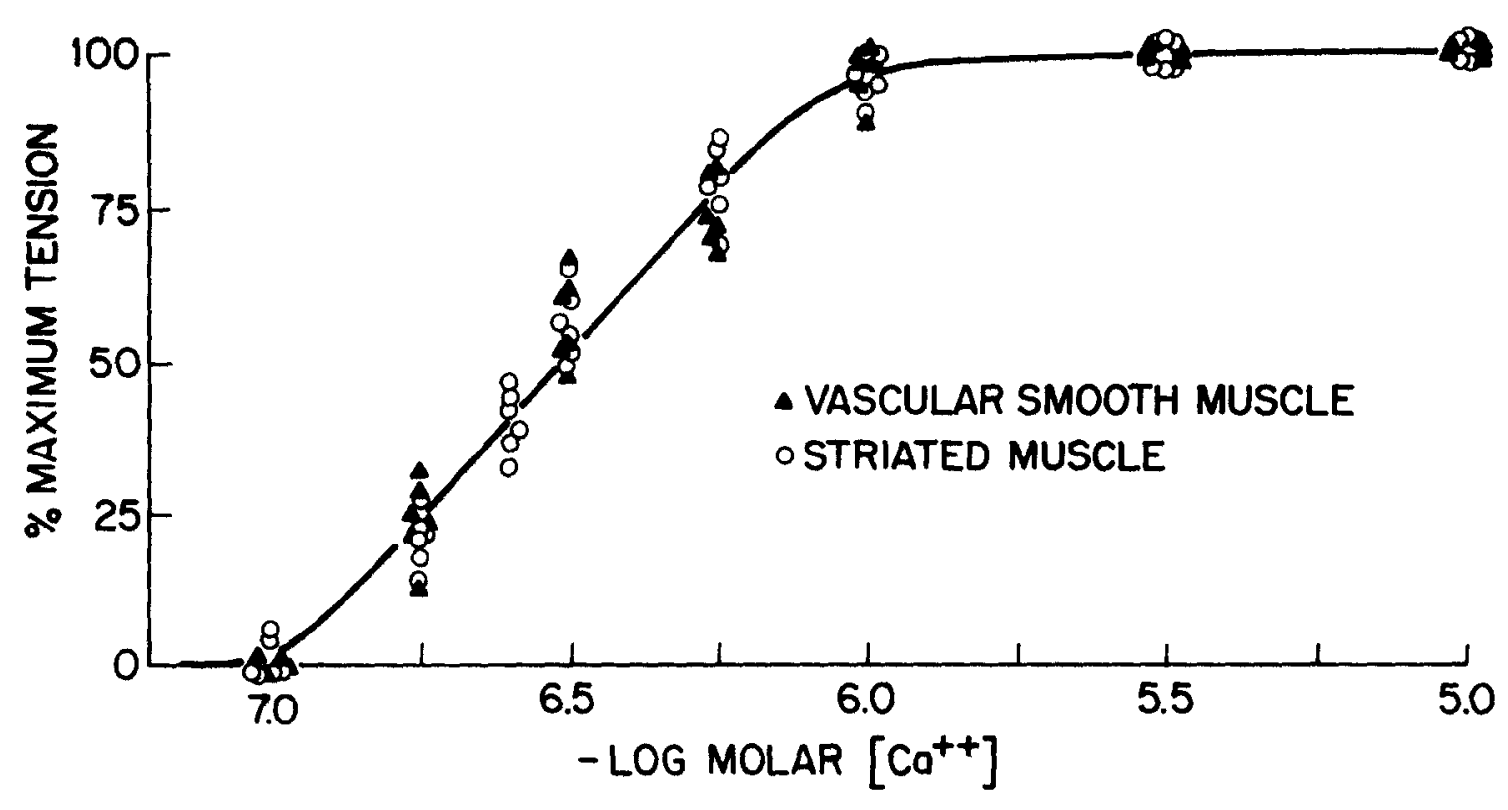

Fig. 2. Effects of concentrations of free calcium on tension development by glycerinated psoas (striated) and vascular smooth muscle fibers. Conditions: temperature, $20^{\circ} \mathrm{C} ; \mathrm{KCl}, 150 \mathrm{mM}$; histidine buffer (pH 6.6), $20 \mathrm{mM}$; ATP and magnesium, 5 $\mathrm{mM}$ : EGTA, $4 \mathrm{mM}$. Free calcium concentration was varied by changing the ratio of calcium to EGTA. Celcium requirements for contraction of these two preparations are virtually identical. (Reproduced by permission of Science. ${ }^{12}$ )

absence of calcium, when pure actin was added to the native actomyosin of skeletal muscle, this otherwise inactive preparation became activated. However, pure myosin, which had failed to activate native actomyosin from skeletal muscle, was found to be effective in activating native actomyosin from molluscan muscle. This technique ${ }^{16}$ has been used extensively to determine whether the regulating system of various types of actomyosin resided in the thin (actin) or thick (myosin) filament. The principle of this technique is presented in Table 1.

\section{Regulation by Troponin and Tropomyosin (Fig. 3, no. I)}

Development of insight into thin filament regulatory system was slow and fraught with controversy. Although Heilbrunn ${ }^{17}$ and Kamada and Kinoshita ${ }^{18}$ established during the 1940s that calcium was clearly involved in excitationcontraction coupling, the mechanism by which it produced activation remained unclear during the 1950s when the Marsh-Bendall relaxing factor ${ }^{19}$ dominated the attention of investigators interested in this process. Furthermore, even in the early 1960s, the preeminent role of calcium as a coupler was questioned because, although it was effective on crude systems such as glycerinated fibers or native actomyosin, it was not necessary for the activation of reconstituted actomyosin that was prepared by combining preparations of pure actin and pure myosin. It was argued that if calcium was not necessary to activate the pure system, it was probably not the primary factor involved in activating the contractile proteins in situ. In the mid 1960s Ebashi and his collaborators ${ }^{14}$ discovered that the missing link in this system was the troponin-tropomyosin system. In the intact resting muscle and in the extract of crude actomyosin, the ATPase activity of actomyosin is normally inhibited by a complex cooperative influence of troponin and tropomyosin. This inhibitory action of the troponin-tropomyosin system is eliminated when calcium combincs

\begin{tabular}{|c|c|c|}
\hline & Calcium & Activated \\
\hline \multicolumn{3}{|c|}{ Evidence for actin regulation } \\
\hline Yes - & native $A M$ & Yes \\
\hline No & native AM & No \\
\hline No & native $\mathrm{AM}+$ pure $\mathrm{A}$ & Yes \\
\hline No & native $A M+$ pure $M$ & No \\
\hline \multicolumn{3}{|c|}{ Evidence for myosin regulation } \\
\hline Yes - & native AM & Yes \\
\hline No & native $A M$ & No \\
\hline No & native $\mathrm{AM}+$ pure $\mathrm{A}$ & No \\
\hline No & native $A M+$ pure $M$ & Yes \\
\hline
\end{tabular}




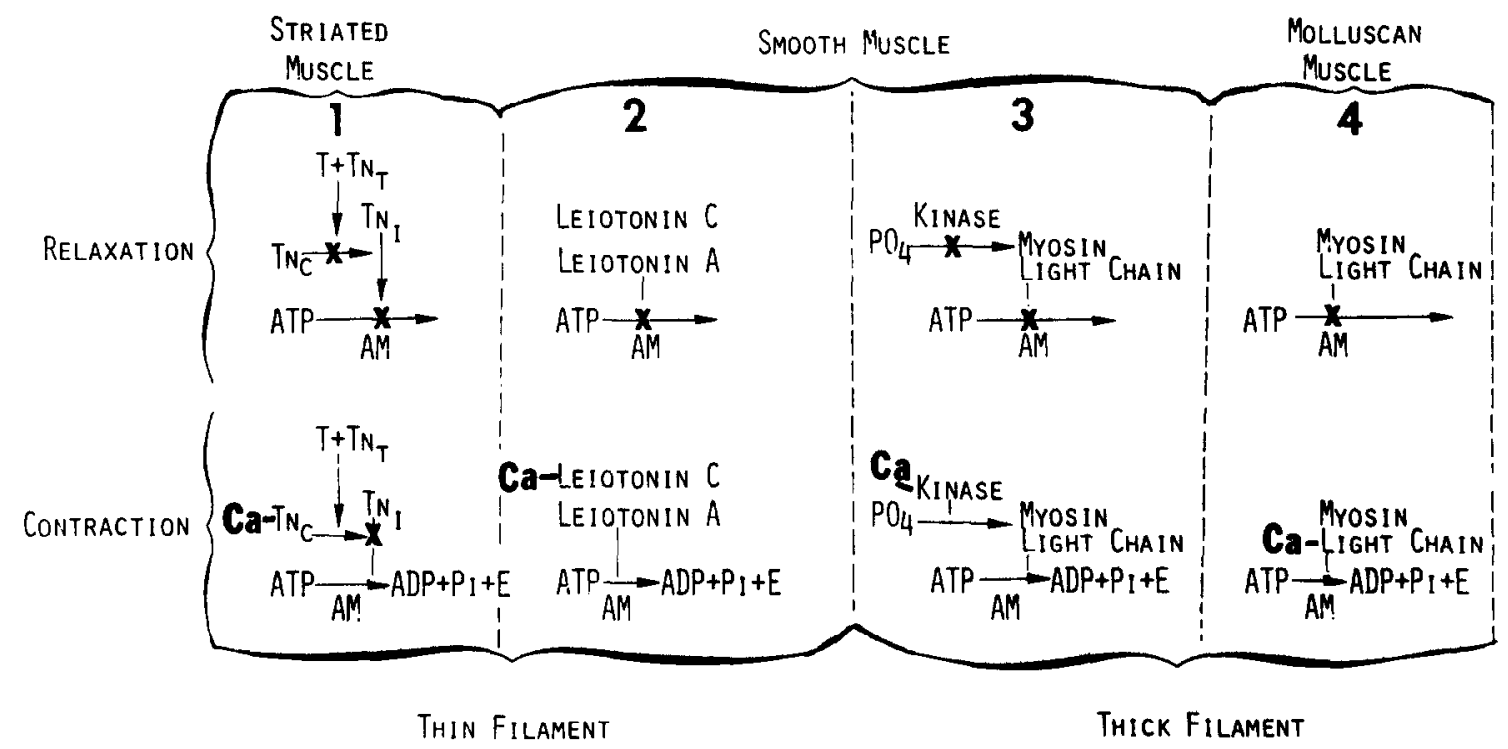

Fig. 3. Thin and thick filament regulatory systems for muscle contraction. Each system is turned on through a quite different calcium-sensitive regulatory mechenism. All require the same concentration of activator calcium. Each system is discussed in the text and described in detail in the following references: $1^{33} ; 2^{7} ; 3^{1,4} ; 4^{1,21}$ The following symbols are used: $T$, tropomyosin: Tn, troponin. Three component troponin molecules are designated Tn, associated with tropomyosin: Tn, calcium binding; and $T n_{i}$ ATPase inhibitory component. The heavy " $X$ " across an arrow indicates that the process is blocked.

with one of the troponins, TN-C. The binding of calcium to TN-C has the same calcium concentration dependence as does the activation of crude actomyosin ATPase. The action of calcium is therefore not a direct activation, but instead a disinhibition of the troponin-tropomyosin system. Because troponin and tropomyosin are bound to actin in the thin filament, both in situ and when extracted in the native state, this regulatory system has been referred to as the actin-linked or thin filament regulatory system. It is well established as the regulatory system for contraction of mammalian skeletal and cardiac muscle.

\section{Regulation by Direct Action of Calcium on the Myosin Light Chain (Fig. 3, no. 4)}

The myosin-linked regulatory system of the molluscan muscle resides in myosin light chains. The light chains can be removed from the myosin molecule by treatment of these components with $10 \mathrm{~m} M$ EGTA ${ }^{20,21}$ In the absence of these light chains, the myosin from molluscan muscle can be activated by actin in the absence of calcium. From this observation it has been inferred that these light chains normally inhibit actin activation and that this inhibition is removed by the presence of calcium. When the 20,000 dalton light chain from molluscan or smooth muscle is added back to this system, its calcium requirement for activation is restored. Myosin light chain from mammalian skeletal or cardiac muscle myosin is not capable of restoring calcium dependence to molluscan myosin. ${ }^{21}$ The regulation of ATPase activity in the molluscan muscle is not altered by phosphorylation of the myosin light chains. ${ }^{22}$

\section{Regulation of Phosphorylation of Myosin Light Chain (Fig. 3, no. 3)}

In contrast to the myosin-linked regulatory system of molluscan muscle, that of mammalian smooth muscle, also myosin-linked, appears to be regulated primarily by phosphorylation of the 20,000 dalton myosin light chain. This conclusion has been documented by several types of observations. In Fig. 4, DiSalvo et al. ${ }^{23}$ demonstrate that this phosphorylation parallels the actomyosin ATPase activity over the relevant range of the calcium concentrations. They also 


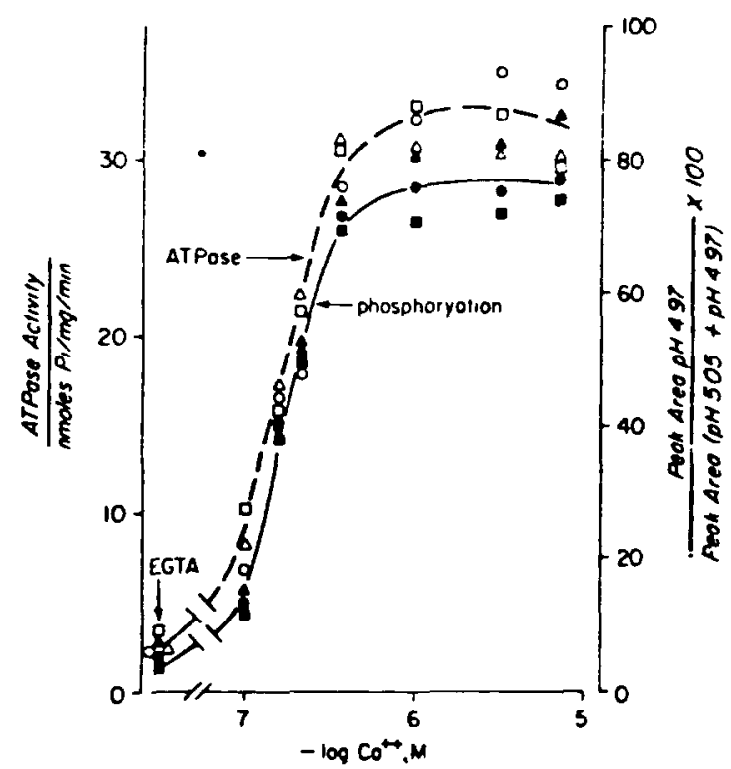

Fig. 4. Calcium dependence of myosin light chain phosphorylation and of actomyosin ATPase activity of bovine aorta. Values are given for three different preparations identified by different symbols. The extent of phosphorylation is expressed as the ratio of the peak area of the phosphorylated polypeptide to the sum of the parent nonphosphorylated band plus the phosphorylated band. (Reproduced by permission of Proceedings of the Society for Experimental Biologr and Medicine. ${ }^{23}$ )

observed that phosphorylation of the light chain precedes ATPase activity, as $50 \%$ of the maximal phosphorylation occurred in only $30 \mathrm{sec}$ incubation, at which time virtually no inorganic phosphate had been relcased from ATP by actomyosin. This suggests that the phosphorylation occurs before the ATP can be hydrolyzed. It is the heavier light chain $(20,000$ dalton $)$ that is phosphorylated in the presence of the calcium (see Fig. 5). Evidence that it is phosphorylation per se rather than the free calcium concentration that activates the ATPase has been presented by Small and Sobieszek.' They observed that the rate of inorganic phosphate liberation from ATP is not altered when free calcium in the solution is chelated by EGTA (see Fig. 6.).

The relationship between phosphorylation and activation of the contractile system of vascular smooth muscle has been demonstrated not only for actomyosin ATPase activity, but also for superprecipitation ${ }^{24}$ and for the contraction of intact living smooth muscle cells. ${ }^{25}$ Dillon et al. ${ }^{25}$ used a quick-freeze technique to study phosphorylation in isolated but intact swine carotid arteries. They observed that the extent of the phosphorylation of the light chain paralleled the

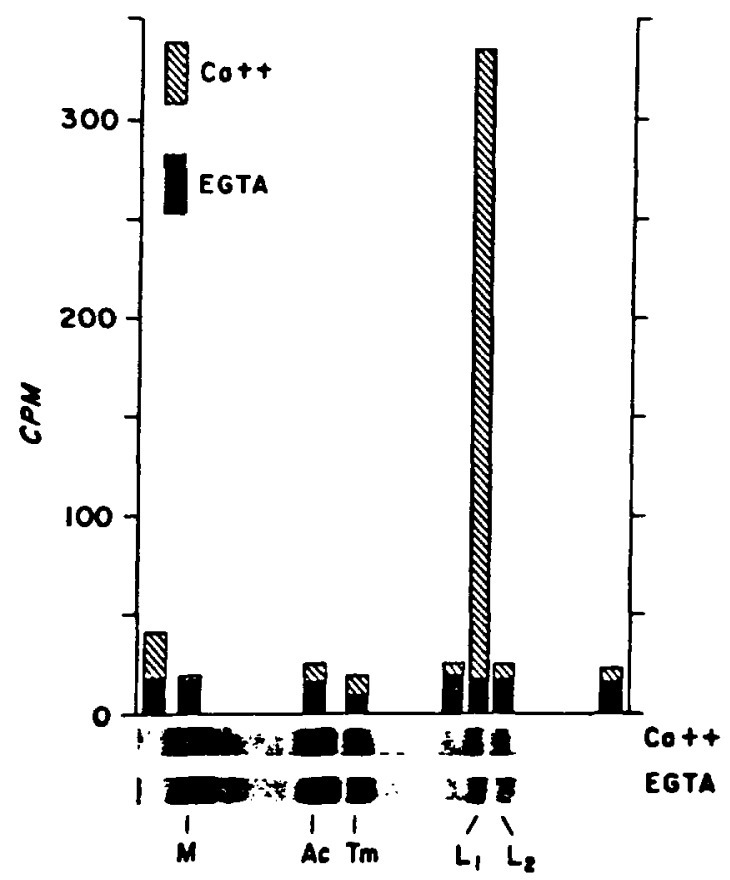

Fig. 5. Incorporation of ${ }^{32} \mathrm{P}$ from ATP in different regions of SDS gel. Striped bars show the extent of ${ }^{32} \mathrm{P}$ incorporation in the presence of $10^{-5} M \mathrm{Ca}^{++}$; whereas the solid bars show incorporation in the presence of $1 \mathrm{mM}$ EGTA. Major bands are identified $M$ (myosin), Ac (actin). Tm (tropomyosin), L, (larger light chain), $L_{2}$ (smaller light chain). The phosphorylation of the larger light chain under the influence of the calcium is evident in the tall crosshatch bar. (Reproduced by permission of Proceedings of the Society for Experimental Biology and Medicine. ${ }^{23}$ )

active state of the contractile process of this muscle.

Further insight has been given into the regulatory role played by the myosin light chain by storing native actomyosin from vascular smooth muscle at $4^{\circ} \mathrm{C} . .^{24.26}$ This cold storage is associated with a progressive loss of the phosphorylatable light chain. With the loss of this light chain, calcium is no longer required for actomyosin ATPase activity or for superprecipitation. These observations suggest that in the fresh native actomyosin the unphosphorylated light chain plays an inhibitory role on the ability of actin to stimulate actomyosin ATPase. Physiologically, in the living tissue, this inhibition is prevented when the light chain is phosphorylated by the calcium-dependent myosin light chain kinase. When the myosin light chain is lost after 5 days of cold storage, the inhibiting effect of this protein is also lost, and the actomyosin ATPase is active in the absence of calcium.

The myosin light chain kinase that effects this 


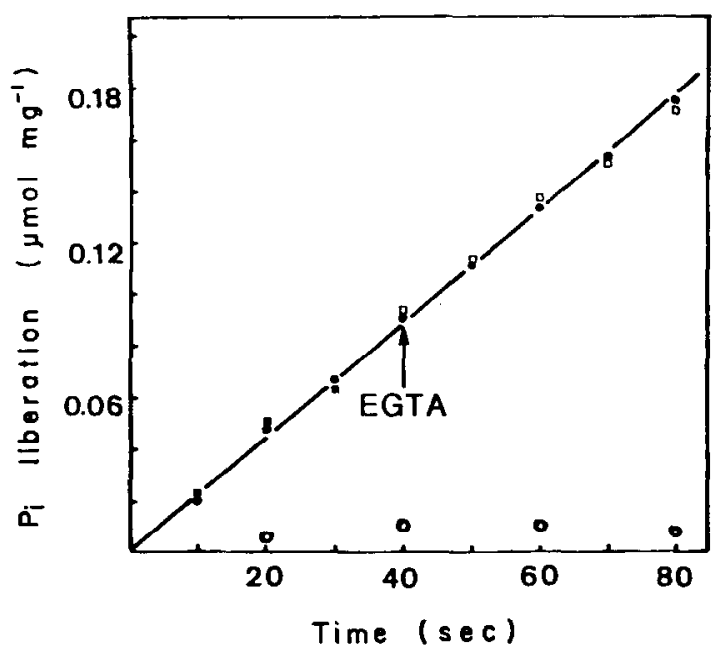

Fig. 6. Effect of $\mathrm{Ca}^{++}$removal on ATPase activity of phosphorylated actomyosin. Closed circles show inorganic phosphate liberation from 0 to $80 \mathrm{sec}$ in the presence of $2 \times 10^{-5} M$ calcium. Squares show an experiment carried out under the same condition except that excess EGTA $(2 \mathrm{~m} M)$ was added after $40 \mathrm{sec}$ of incubation. Open circles show a controlled experiment for which the same amount of EGTA was added prior to the initiation of the study by the addition of ATP. As shown, the removal of calcium after $\mathbf{4 0}$ sec did not affect the rate of ATP hydrolysis. Other measurements show that the extent of myosin phosphorylation was unchanged following the addition of EGTA. It was concluded that ATPase was not directly dependent on the presence of free $\mathrm{Ca}^{++}$but that it does require the presence of a phosphorylated myosin light chain. (Reproduced by permission of International Review of Cytology. ')

phosphorylation is a specific calcium-requiring enzyme. ${ }^{4}$ It has a molecular weight of approximately 130,000 daltons and is activated by calmodulin (16,500 daltons). Calmodulin is present in all tissues, but the kinase that it activates is specific for smooth muscle. The larger molecule must be activated by calmodulin before it can phosphorylate the light chain, and calmodulin requires a concentration of calcium greater than $10^{-7}$ before it can activate the kinase. Recently it has been observed that $5 \mu M$ exogenous calmodulin increased the speed of tension development of skinned smooth muscle, by tenfold but had no effect on this variable when skeletal muscle was used. ${ }^{27}$

Conti and Adelstein ${ }^{28}$ have observed that when myosin light chain kinase is itself phosphorylated, the affinity of the myosin kinase for calmodulin is decreased. This should and does result in a decrease in myosin kinase activity. Silver and DiSalvo ${ }^{29}$ have observed an approximately $10 \%$ decrease in phosphorylation of myosin light chain from aortic smooth muscle in the presence of a cardiac protein kinase, which phosphorylates the myosin light chain kinase. When protein kinase was stimulated by $2 \mathrm{mM}$ cyclic AMP, phosphorylation of the myosin light chain was reduced by approximately $50 \%$. Obviously, cyclic AMP does not have a stimulating effect on myosin light chain kinase. Since the magnitude of actomyosin activation is a direct function of myosin light chain phosphorylation, the reduction in its phosphorylation produced by this cyclic nucleotide may have an important modulating effect on contraction. In Fig. 7, Adelstein and Eisenberg ${ }^{4}$ depict a cascade of events utilizing this system, beginning with the increase in cyclic AMP resulting from $\beta$-adrenergic activation and ending with smooth muscle relaxation. Hoar et al. ${ }^{30}$ have shown that in the chemically skinned smooth muscle fiber, the addition of cyclic-AMP-dependent protein kinase plus cyclic AMP resulted in a decrease in smooth muscle tension. Silver and DiSalvo ${ }^{31}$ have observed that bovine coronary arteries made to contract by stimulation with $\mathrm{KCl}$ were relaxed in a dose-dependent fashion by addition of isoproterenol to the bath. The magnitude of relaxation was paralleled by an increase in the activity of tissue protein kinase. Adenosine may produce relaxation by a similar mechanism. ${ }^{32}$

Myosin light chain kinase is dephosphorylated by a specific phosphatase found in smooth muscle and in other tissue. ${ }^{34}$ Action of these phosphatases lower the actin-activated ATPase activity of phosphorylated myosin. This phosphorylase can also dephosphorylate myosin light chain kinase. Activity of the phosphorylase plays an obvious role in vascular smooth muscle relaxation, but factors that may influence the activity of the phosphatases are not understood. This is potentially a second site for modulating the regulatory system for vascular smooth muscle.

Dillon et al. ${ }^{25}$ have recently made observations that implicate phosphatase and myosin light chain dephosphorylation in a mechanical process of the contractile protein of vascular smooth muscle that may be responsible for the high economy of force maintenance in the blood vessel wall. ${ }^{35}$ Their study of the mechanical response of smooth muscle in strips of pig carotid artery stimulated with $\mathrm{KCl}$ is illustrated in Fig. 8. Following stimulation, load-bearing capacity gradually reached a maximum in about $5 \mathrm{~min}$ and was maintained thereafter. Using a measure 


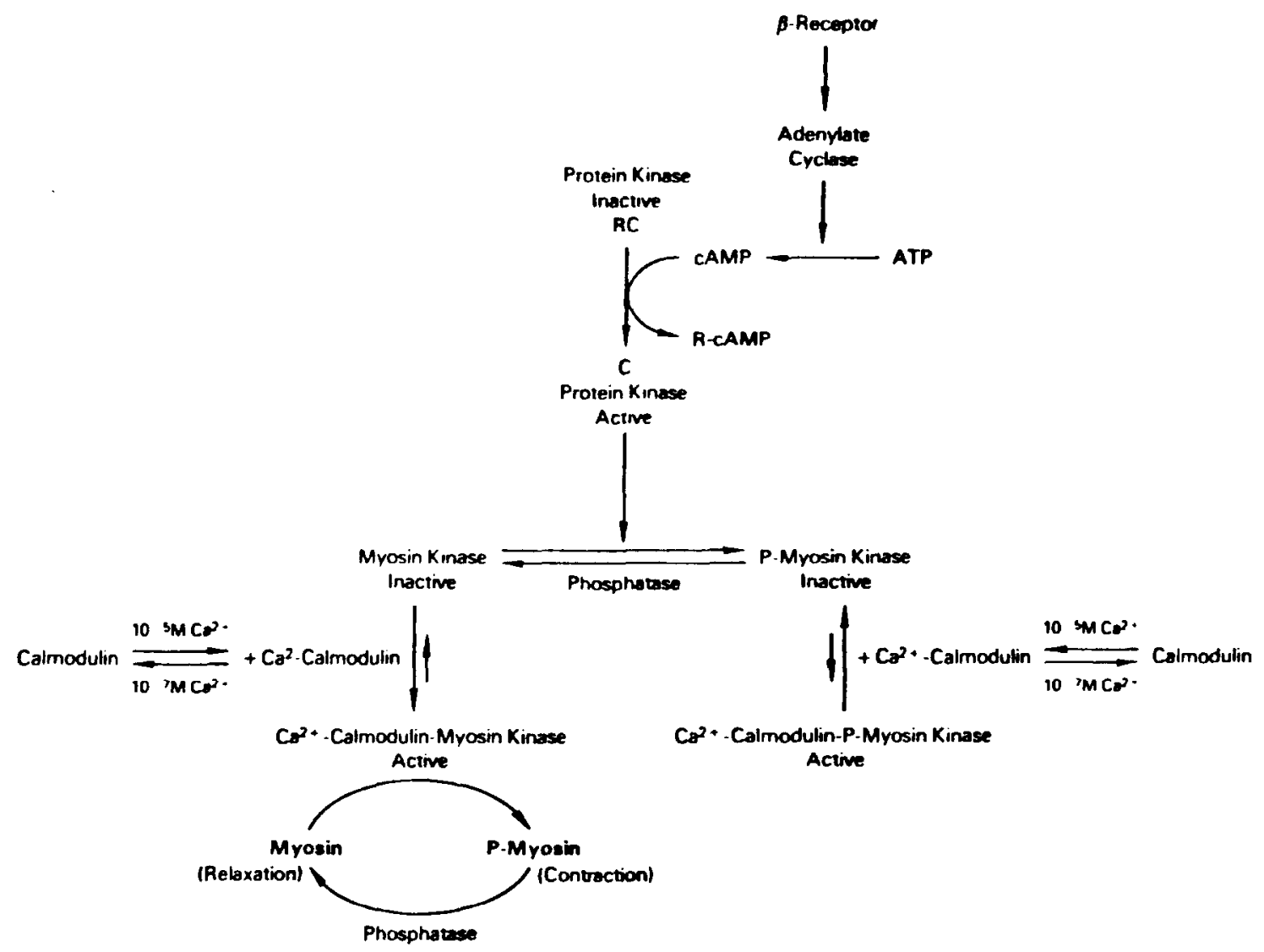

Fig. 7. Regulation of smooth muscle contraction by $\mathrm{Ca}^{2+}$ and $\mathrm{CAMP}$. $\mathrm{Ca}^{2+}$ : Calcium, at a concentration of $10^{-5} \mathrm{M}$, binds to calmodulin, and the $\mathrm{Ca}^{2+}$-calmodulin complex binds to the inactive form of myosin kinase. The active kinase catalyzes phosphorylation of the myosin light chain, which results in a form of myosin that can interact with actin, causing smooth muscle contraction. A decrease in the $\mathrm{Ca}^{2+}$ concentration to $10^{-7} \mathrm{M}$ leads to a dissociation of calcium and calmodulin from the active kinase, which results in an inactive form of the kinase. Under these conditions, myosin phosphatase, which is not dependent on $\mathrm{Ca}^{2+}$ for activity. dephosphorylates myosin, causing smooth muscle relaxation. CAMP: Stimulation of the beta-receptor by epinephrine results in an increase in adenylate cyclase activity and hence an increase in cyclic AMP production. This results in an active form of protein kinase (C). Phosphorylation of the myosin kinase by protein kinase weakens the binding of $\mathrm{Ca}^{2+}$-calmodulin to the myosin kinase, and hence favors the inactive form of the myosin kinase. Dephosphorylation of the myosin kinase by phosphatase restores the kinase to the form that binds $\mathrm{Ca}^{2+}$-calmodulin strongly. The length of the arrows between the inactive and active forms of myosin kinase qualitatively indicates the direction in which the equilibrium is shifted. Inactivation of myosin kinase by phosphorylation favors the dephosphorylated form of myosin and results in smooth muscle relaxation. This may explain how epinephrine acts to relax certain smooth muscles. $R$, regulatory subunit of cAMP-dependent protein kinase: $C$. catalytic subunit of cAMP-dependent protein kinase. (Reproduced by permission of Annual Review of Biochemistry.")

of $V_{\max }$ obtained from force-velocity relationships, these investigators were able to estimate cross-bridge cycling rates. In response to this stimulation with $\mathrm{KCl}$, the $\mathrm{V}_{\max }$ peaked in $30 \mathrm{sec}$, then fell off, reaching a constant low value after $5 \mathrm{~min}$. Measurement of the ratio of phosphorylated to dephosphorylated myosin light chain indicated that this ratio followed the $V_{\text {max }}$ rather than the load-bearing capacity of the muscle. Thus, it appears that the light chain was dephosphorylated by a phosphatase, and that dephosphorylated cross-bridges remain attached, main- taining the load-bearing capacity, but were noncycling, conserving ATP. The investigators called these "high economy" load-bearing connections "latch-bridges."

\section{Regulation by Leiotonin on the Thin Filament (Fig. 3, no. 2)}

As convincing as these arguments seem in support of myosin light chain phosphorylation as the regulator of vascular smooth muscle contraction, there is at least one well documented alternative. Ebashi and coworkers, in $1975,{ }^{36}$ discov- 


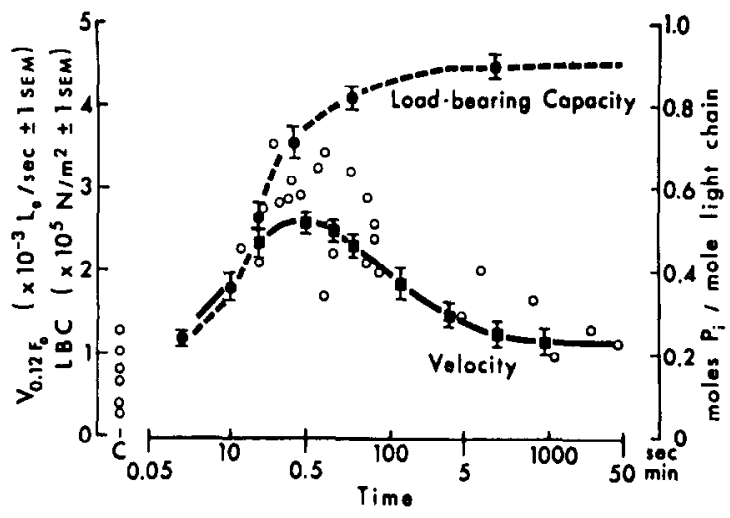

Fig. 8. Mechanical and chemical correlates in response to stimulation of smooth muscle from the pig carotid with potassium. The load-bearing capacity (solid circles), shortening velocity at an afterload of $0.12 \mathrm{~F}_{0}$ (solid squares), and fractional phosphorylation of myosin light chain (open circles) are plotted as a function of time after the potassium stimulation on a log scale. The mechanical data are averages of five different tissues. Each phosphorylation determination represents a single tissue, frozen at the indicated time $(n=30)$. The velocity of shortening, which is an index of myosin bridge cycling rate and the light chain phosphorylation, follow parallel activity patterns that subside $5 \mathrm{~min}$ after stimulation, while the load-bearing capacity remains high. (Reproduced by permission of Science. ${ }^{25}$ )

ered an 80,000 dalton protein component of native actomyosin from chicken gizzard. In $1977,{ }^{37}$ they reported that this protein, which they called leiotonin, was essential for activation of actomyosin in the presence of calcium. It differed from troponin in that its affinity for actin was greater than for tropomyosin. Nevertheless, tropomyosin is also essential for full activation of ATPase activity and superprecipitation of actomyosin by leiotonin. These investigators reported another difference from skeletal muscle regulation; they demonstrated that pure actin and myosin from chicken gizzard did not have ATPase activity, even in the presence of calcium, unless the regulatory proteins, tropomyosin and leiotonin, were present. Evidence in support of this difference is shown in Fig. 9. Smooth muscle contractile protein is activated only in the presence of the regulatory proteins and calcium, whereas skeletal muscle is activated in the absence of regulatory proteins and calcium but depressed by the presence of regulatory proteins without calcium; this depression is overcome in the presence of calcium.

Leiotonin is comprised of two molecules: (1)

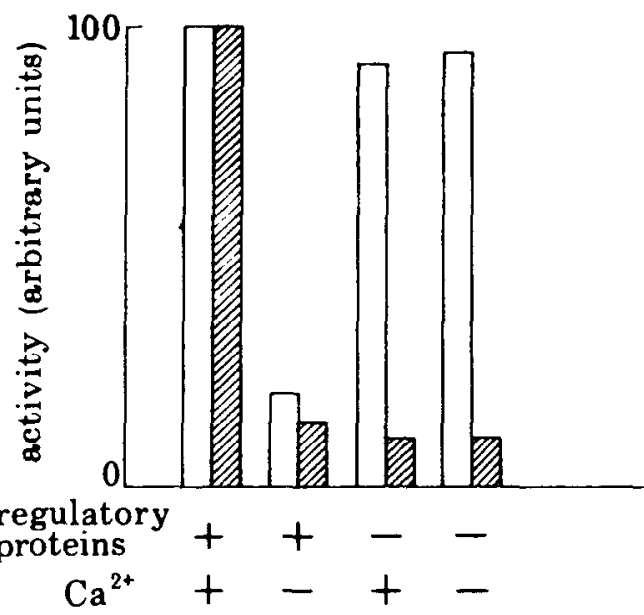

Fig. 9. Actomyosin ATPase activity of reconstituted actomyosin of rabbit skeletal (open bars) and chicken gizzard (hatched bars) muscles. The regulatory protein for skeletal muscle is a complex of almost pure troponin and tropomyosin: that from gizzard was a crude mixture containing leiotonin and tropomyosin. The skeletal muscle shows almost full ATPase activity in the absence of regulatory proteins whether or not calcium ion is present. In contrast, that from the gizzard remains in a depressed state in the absence of regulatory proteins, suggesting that the latter are necessary for activation of the ATPase activity. (Reproduced by permission of the Proceedings of the Royal Society of London. ${ }^{33}$ )

leiotonin $\mathrm{A}$, the relatively high molecular weight, 80,000 dalton, protein and (2) leiotonin $\mathrm{C}$, a 17,000 dalton protein. Leiotonin $\mathrm{C}$ is a calcium binding protein, which, although clearly different from calmodulin, can be substituted by calmodulin in support of activation of actomyosin ATPase by leitonin A. ${ }^{7}$ One problem that must be reconciled in supporting the leiotonin mechanism for actomyosin regulation relates to the stoichiometry of the proteins. There is only one leiotonin molecule for every 10 tropomyosin molecules and one tropomyosin molecule for each of $3+$ actin molecules. It is difficult to conceive of a system where one leiotonin molecule would have such a broad regulatory influence.

Ebashi has concluded that in gizzard smooth muscle the calcium-sensitive process is in the thin filament, though the mechanism and the working of the component parts remain to be explained. A similar leiotonin regulator system has been described for bovine aortic smooth muscle. ${ }^{4}$ Not only have Ebashi and coworkers ${ }^{7}$ found this thin-filament-related regulatory system in smooth muscle, but they have also 
presented the following evidence that argues against the importance of the myosin light chain phosphorylation mechanism for actomyosin regulation. (1) Whereas leiotonin fully activated the ATPase activity of a mixture of myosin, actin, and tropomyosin in the presence of calcium, it phosphorylated myosin only weakly. In contrast, the combination of the myosin light chain kinase and calmodulin fully phosphorylated the myosin, but only weakly activated the ATPase. (2) When phosphatase was added to native actomyosin, superprecipitation occurred in the presence of calcium, despite the lack of phosphorylation of the myosin light chain. (3) Phosphorylation of this system was very weak at $\mathrm{pH} 6.7$, despite a full activation of the ATPase.

Strong, even outspoken defense may be found in support of each of the proposed regulatory mechanisms. Bearing on the difference in findings on this subject, Nonomura and Ebashi ${ }^{7}$ state that their results "suggest that careful experimental planning is indispensable for physiologic experiments to overcome any tendency to arrive at superficial understanding." Small and Sobieszek' deal with results in support of leiotonin by concluding that "much of their evidence, however, may be explained in terms of a contamination of the different preparations with light chain kinase and possibly also the activator protein that confers calcium sensitivity to the kinase."

In view of the current state of the art, both systems must be considered as potentially valid because of both the preeminence of the investigators in each camp and the possibility that smooth muscle may have a dual regulatory system involving both thick and thin filaments. Marston et al. $^{38}$ have recently studied the calcium regulatory system of pig aorta and of turkey gizzard smooth muscle actomyosin using myosin and actin competition tests. They have concluded from these and from more detailed studies of the regulatory systems that smooth muscle has both thin filament and myosin-linked calcium regulatory systems.

\section{CELLULAR SITES FOR THE REGULATION OF INTRACELLULAR CALCIUM}

There is little question that the interaction of the contractile proteins responsible for contraction and relaxation is regulated by the intracellular concentration of ionized calcium. The identi- fication of the anatomical structures responsible for the raising and lowering of ionized calcium remains a major objective in vascular smooth muscle research. In striated muscles, the sarcoplasmic reticulum is the intracellular structure that accumulates calcium during relaxation and from which the calcium that activates contraction is released by the action potential. In vascular smooth muscle, the following structures have been implicated in this function: (1) cell membrane, (2) sarcoplasmic reticulum, and (3) mitochondria.

\section{Cell Membrane}

The plasma membrane is an important barrier to calcium entry and it contains regulatory devices that function in the maintenance of intracellular calcium levels. Additionally, the plasma membrane plays an important role in cell-to-cell communication of ionic and metabolic information via cell junctions. ${ }^{2}$

Ultrastructural observations indicate that the cell membrane is about 7-10 nm thick and is composed, as in most other tissues, of three layers ( 2 osmiophillic layers, $2.5 \mathrm{~nm}$ thick, separated by a dense layer, $3 \mathrm{~nm}$ thick). The cell membranc of vascular smooth muscle is invaginated to form surface vesicles or caveolae (50-80 $\mathrm{nm}$ in diameter). Devine et al..$^{39}$ have shown that colloidal lanthanum, an extracellular marker, enters the surface vesicles, and therefore, these vesicles are in direct communication with the extracellular space. These flask-like structures increase the effective surface area of the membrane by $25 \%-75 \%$. Conventional electron microscopic techniques, ${ }^{40.41}$ as well as freezefracture studies, ${ }^{42}$ show that the surface vesicles form a linear array along the longitudinal axis of the smooth muscle cell. Although the vesicles are found on all surfaces of the cell membrane, they are more numerous on the outer (towards adventia) and interfaces of muscle cells than on the inner (towards lumen) surfaces. ${ }^{43-45}$ Recent observations of membrane systems in mouse coronary arteries indicate that vesicles may occur singly or in more complex forms that resemble chains of beads fused end-to-end. ${ }^{45}$ These beaded tubules may be composed of as many as 17 vesicles and often extend deep into the cell (Fig. 10). Branched arrays of interconnected vesicles were also observed. The number of vesicles in the membranc are dependent on the 


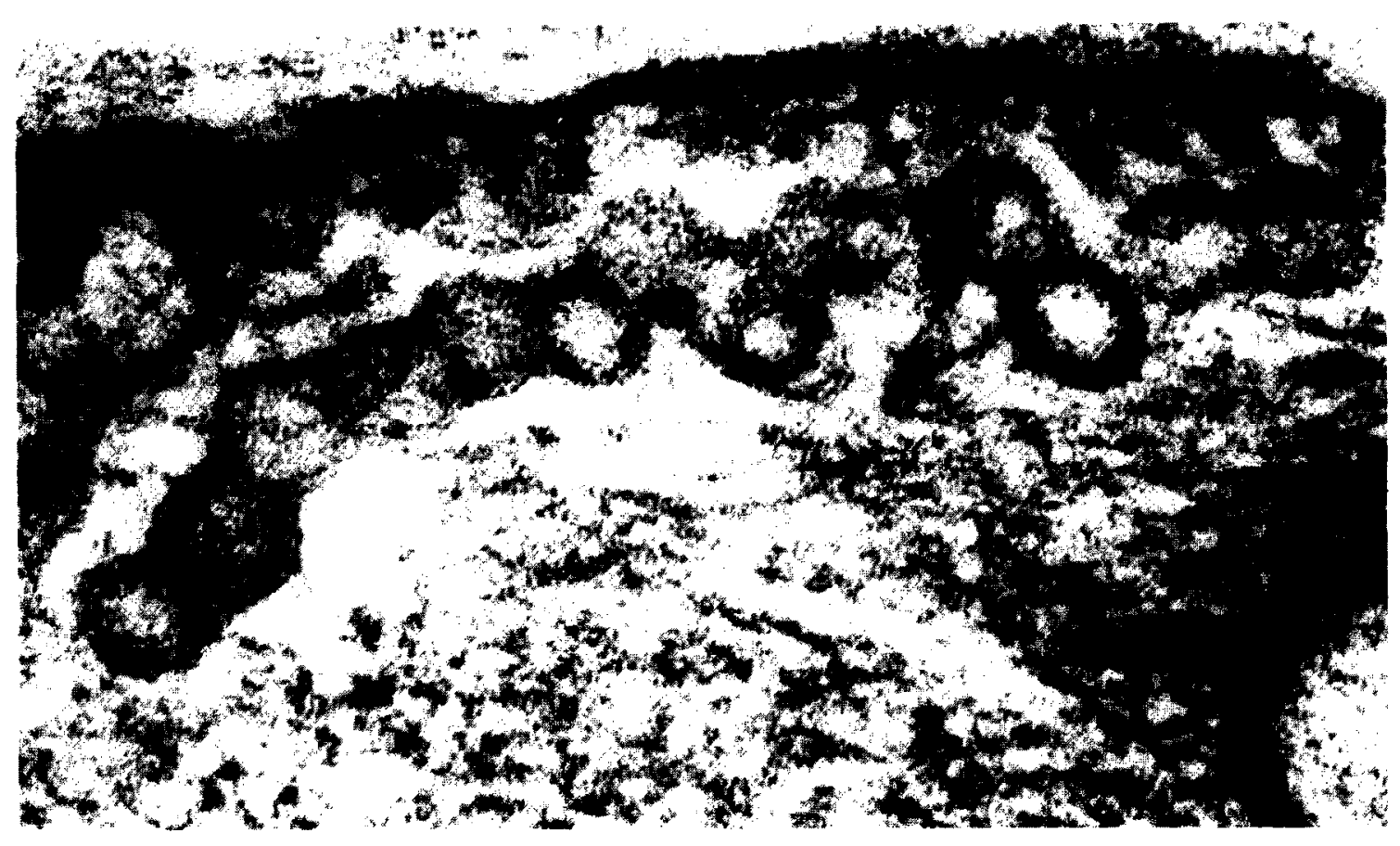

Fig. 10. Surface vesicles in smooth muscle cells of mouse coronary artery. The surface vesicles in vascular smooth muscle may occur in complex forms that resemble elongated beaded tubules. This particular example is composed of approximately 17 vesicles fused end-to-end. The arrow indicates the ostium of the beaded tubules. The magnification in this electron micrograph is $134,500 \times$. (Reproduced by permission of Journal of Ultrastructural Research. ${ }^{45}$ )

age of the animal; vascular tissue from older animals have many more vcsicles than that from younger animals. ${ }^{46}$ Unlike vertebrate vascular smooth muscle, the surface vesicles of the aorta and vena cava of the diamondback turtle have parallel striations or shelves within the vesicular membrane. ${ }^{47}$

The surface vesicles are believed to be analogous to the transverse tubules ( $T$ tubules) of striated muscles. Thus, they have been proposed to play a role in ion transfer between intracellular structures, such as the sarcoplasmic reticulum and mitochondria. Although actual transfer of ions has not been demonstrated, a close structural association between the membranes of the sarcoplasmic reticulum and mitochondria and those of the surface vesicles is often observed in electron micrographs of vascular smooth muscle. ${ }^{2,39,45}$ The sarcoplasmic reticulum surface vesicle contacts are called "couplings" and are bridged by small electron-dense structures. These couplings may be sites at which calcium is released during the action potential, as in cardiac muscle (Fig. 11).

The surface membrane adjacent to the vesicles has also been proposed to play a role in ion transfer. Freeze-fracture studies ${ }^{42,48}$ reveal that these regions of the cell membrane contain a high density of membrane particles on the cytoplasmic membrane leaflet as compared to the external leaflet. There is an absence of these particles on the actual vesicle. ${ }^{49}$ The particles are thought to be membrane proteins important for ion binding and pumping.

\section{Sarcoplasmic Reticulum}

The sarcoplasmic reticulum in vascular smooth muscle, as in striated muscle, is believed to fulfill some function in the storage, uptake, and release of calcium. The use of extracellular markers (ferritin, horseradish peroxidase, and colloidal lanthanum) has demonstrated that the sarcoplasmic reticulum is a true intracellular membrane system, rather than a system of tubules communicating with the extracellular space. ${ }^{39,47,50}$ The smooth tubules of the sarcoplasmic reticulum are continuous with the rough endoplasmic reticulum and with the nuclear membrane. The form and distribution of this membrane system is best demonstrated in vascular tissues postfixed in osmium-ferrocyanide after initial fixation in an aldehyde solution containing $5.0 \mathrm{mM} \mathrm{CaCl}{ }_{2}{ }^{45,51}$ Using this technique, the membranes of the sarcoplasmic reti- 


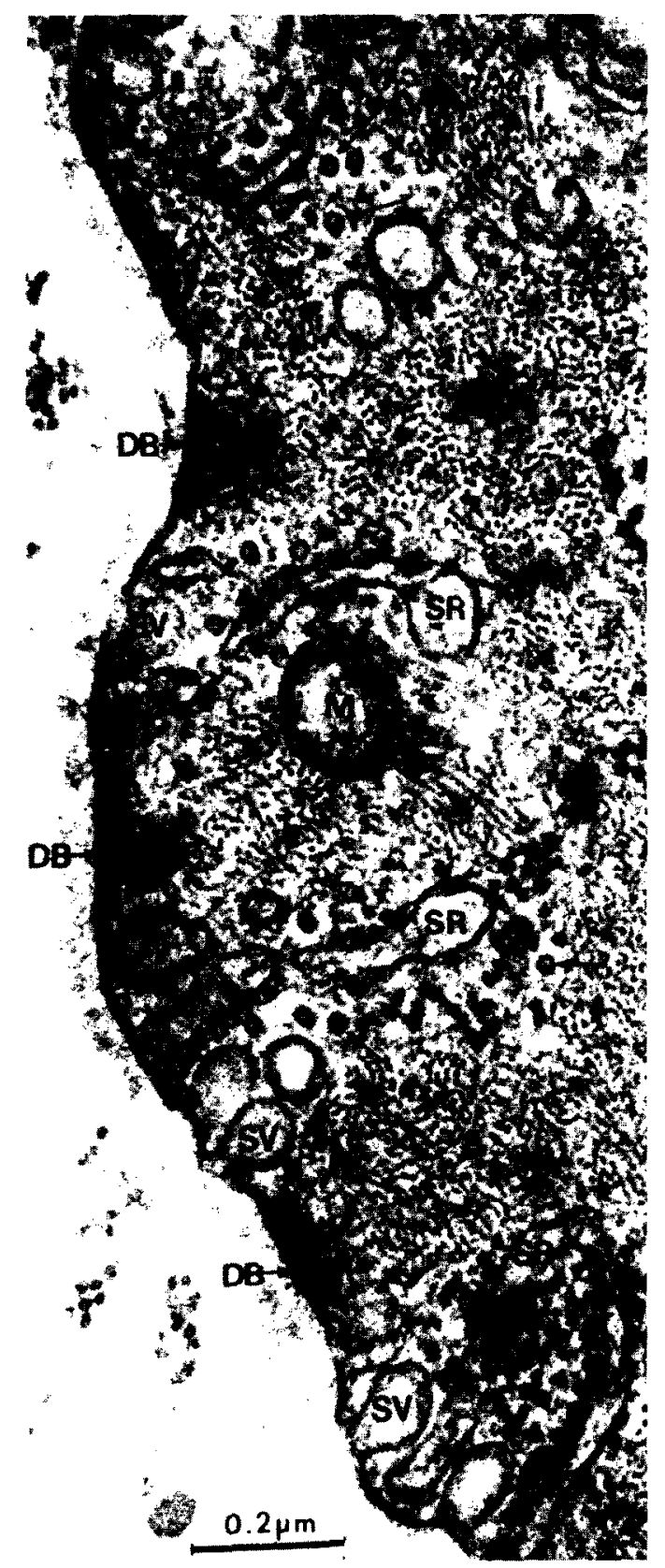

Fig. 11. Structural association between surface vesicles and sarcoplasmic reticulum. This electron micrograph illustrates the close anatomical association between the membranes of the sarcoplasmic reticulum (SR) and those of the surface vesicles (SV) in a smooth muscle cell of the rabbit main pulmonary artery. Four portions of the sarcoplasmic reticulum approach membranes associated with surface vesicles. Dense bodies (DB) alternate with peripheral sarcoplasmic reticulum membranes and surface vesicles. The arrows indicate microtubules and the upper case " $M$ " indicates a mitochondrian. (Aeproduced by permission of Journal of Cell Biology. ${ }^{52}$ ) culum and the nuclear envelope become intensely opaque, whereas the membranes making up the Golgi apparatus do not.

Quantification of the volume of sarcoplasmic reticulum within the smooth muscle cell has been performed by the use of tilt-stage electron microscopy and integration by weight of resulting montages. ${ }^{39}$ Tonic smooth muscles (rabbit main pulmonary artery and aorta), which do not spontaneously generate action potentials and respond to excitatory agents by graded depolarization, contain from $5 \%$ to $7.5 \%$ sarcoplasmic reticulum (nucleus and mitochondria-free cell volume), whereas phasic smooth muscles (rabbit portal-anterior mesenteric vein) contain from $2 \%$ to $3 \%$ sarcoplasmic reticulum. It has been observed that smooth muscles that contain a large volume of sarcoplasmic reticulum have the ability to maintain contractions in the absence of calcium, whereas smooth muscles with less sarcoplasmic reticulum do not.

The possibility that the sarcoplasmic reticulum may be a functional source of activator calcium in vascular smooth muscle is suggested by electron microscopic studies employing electron-opaque divalent cations (e.g., strontium) that may substitute for calcium. Vascular tissues incubated in strontium-containing solutions have electron-opaque deposits in the sarcoplasmic reticulum that have been identified as strontium by electron probe analysis. ${ }^{52,53}$ Recently, electron probe analysis of unfixed, frozen, dried thin sections has localized calcium to the sarcoplasmic reticulum of vascular smooth muscle. ${ }^{54}$ Cytochemical studies, using pyroantimonote or oxalate to localize calcium, have also demonstrated granules (presumably, calcium pyroantimonote and calcium oxalate, respectively) associated with sarcoplasmic reticulum of rat and pig pulmonary artery, ${ }^{55}$ rat aorta, ${ }^{56}$ and pig coronary artery. ${ }^{57}$

\section{Mitochondria}

The mitochondria may also serve as a store of calcium in vascular smooth muscle. As in other tissues, these cigar-shaped organelles in vascular smooth muscle are bound by a double membrane and contain prominent cristae. ${ }^{46}$ The mitochondria are often closely associated with the surface vesicles (4-5 nm between the mitochondrial and vesicular membrane).$^{39,53,58}$ Incu- 
bation of vascular smooth muscle in strontiumor barium-containing solutions produces visualization of intramitochondrial electron-opaque granules. ${ }^{52,53,59}$ Electron probe analysis indicates that these granules exhibit energy peaks characteristic of strontium and barium, respectively. ${ }^{52,60}$ A very large energy peak corresponding to calcium has also been observed in mitochondria of vascular smooth muscle using electron probe analysis. ${ }^{60}$

\section{MEMBRANE ELECTRICAL EVENTS}

The intracellular level of activator calcium in vascular smooth muscle is influenced by the electrical state of the cell membrane. Changes in the membrane potential and generation of action potentials constitute the electrical events that influence contractile responses of vascular smooth muscle.

\section{Membrane Potential}

The resting membrane potential of vascular smooth muscle as measured by intracellular microelectrode techniques ranges from -40 to $-75 \mathrm{mV} .{ }^{61}$ Two major cellular processes are considered to be responsible for this transmembrane potential difference: (1) an unequal distribution of major ions associated with differing membrane permeabilities to the respective ions; and (2) an electrogenic transport of ions. The former membrane process results in the generation of a diffusion potential; whereas the latter process results in a separation of electrical charge due to unequal stoichiometric exchange. Both membrane processes are important determinants of the resting membrane potential, and therefore both affect the contractile properties of the vascular smooth muscle cells.

Analysis of monovalent ion fluxes and measurement of membrane potential by electrophysiologic techniques have been important methods to study the processes involved in the contribution of passive membrane permeability to vascular responsiveness. For example, Kreye and coworkers ${ }^{62,63}$ have observed that the passive permeability of radioactive chloride ions is increased by norepinephrine, and nitroprusside or nitroglycerin reduce the magnitude of this norepinephrine-induced increase. They postulated that the relaxing effect of nitroprusside and nitroglycerin is due to a membrane hyperpolari- zation effected by a reduction in membrane permeability to chloride ion resulting in a buildup of negative charge within the cell. Harder and Coulsen $^{64}$ observed that diethystibesterol hyperpolarized dog coronary arteries from $-51 \mathrm{mV}$ to $-64 \mathrm{mV}$ and input resistance decreased from 10 megohms to 5 megohms. They suggested that membrane hyperpolarization in response to this drug was due to a mechanism that increases potassium conductance. Graded increases in the concentration of extracellular potassium ion cause depolarization of vascular smooth muscle. $^{65}$

A reduction in the extracellular concentration of potassium below physiologic levels also causes depolarization of vascular smooth muscle. ${ }^{65}$ This membrane depolarization is the result of a decrease in the activity of an electrogenic sodium pump that normally contributes to the resting membrane potential. ${ }^{66}$ The net effect of this pump is to extrude sodium ions against an electrochemical gradient and to take up potassium ions against a diffusion gradient but down its electrical gradient. This active transfer of ions is driven by the hydrolysis of adenosine triphosphate (ATP). Based on the analysis of ouabainsensitive ion movements, the stoichiometry of the reaction is believed to be three sodium ions moved out of the cell in exchange for two potassium ions pumped in per molecule of ATP hydrolyzed ${ }^{67}$ Thus, the pump is electrogenic, since a net excess of positive charge is moved out of the cell.

Sodium-potassium adenosine triphosphatase (ATPase) is the enzyme that provides the mechanism for the electrogenic pumping of sodium and potassium. ${ }^{68,69}$ Quantitative estimates of the activity of this enzyme have been difficult because the structural complexity and size of the vessel wall have limited the application of conventional biochemical techniques.

Classically, the activity of any ATPase is measured as the amount of inorganic phosphate liberated from the hydrolysis of ATP. Experimental conditions then define the sensitivity of the enzyme to sodium and potassium and the dependence of its activity upon specific interventions. Until recently, there has been very little application of biochemical principles to the study of sodium-potassium ATPase in vascular smooth muscle. 
Table 2. Sodium-Potassium ATPase Activity in Vascular Smooth Muscle

\begin{tabular}{|c|c|c|c|}
\hline $\begin{array}{c}\text { Species and } \\
\text { Type of Blood Vessel }\end{array}$ & Cell Fraction & $\begin{array}{l}\text { Sodium-Potassium ATPase Activity } \\
(\mu \text { mole Pi/mg Protein/hr) }\end{array}$ & Reference \\
\hline Rat aortic media & Microsomes & 19 & Allen and Seidel ${ }^{73}$ \\
\hline Dog aorta & Microsomes & 12 & Allen et al. ${ }^{72}$ \\
\hline Cat aorta & $\begin{array}{l}\text { Whole tissue } \\
\text { homogenate }\end{array}$ & 0.087 (mmole $\mathrm{Pi} / \mathrm{g}$ wet weight $/ \mathrm{hr}$ ) & Bonting et al. ${ }^{70}$ \\
\hline Bovine aorta & Microsomes & 10.5 & Hess and Ford ${ }^{76}$ \\
\hline Dog mesenteric arteries & Microsomes & 7.8 & Limas and Cohn ${ }^{76}$ \\
\hline Sheep carotid artery & Microsomes & 2 & Preiss and Banaschak ${ }^{77,78}$ \\
\hline Bovine carotid artery & Microsomes & 2.9 & Preiss and Banaschak ${ }^{79}$ \\
\hline Rabbit aorta & Microsomes & 0 & Verity and Bevan ${ }^{71}$ \\
\hline
\end{tabular}

In 1961, Bonting et al. ${ }^{70}$ reported that tissue homogenates of cat aorta contained $\mathrm{Na}-\mathrm{K}$ ATPase activity that was ouabain sensitive (see Table 2). The Na-K ATPase activity was approximately $30 \%$ of the total magnesiumdependent ATPase activity. Eight years later, Verity and Bevan ${ }^{71}$ prepared subcellular fractions by differential centrifugation of homogenates of rabbit aorta. Most of the magnesiumdependent ATPase activity was found in the microsomal fraction $(102,000 \mathrm{~g})$. However, these investigators were unable to demonstrate stimulation of the enzyme with sodium and potassium and inhibition of the activity with ouabain in this preparation. During the 1970 s, many investigators ${ }^{72-81}$ demonstrated $\mathrm{Na}-\mathrm{K}$ ATPase activity in a variety of blood vessel types from several different animal species. The activities of the enzyme in these different membrane preparations show considerable variability $\mathrm{Ta}$ ble 2). Although it is certain that differences in enzyme activity exist at different levels of the circulation and in different animal species, a portion of the variability is probably due to the development of adequate preparative techniques. Alternative methods for estimation of electrogenic transport have therefore played an important role in the evaluation of Na-K ATPase in vascular smooth muscle. These alternative methods are: (1) potassium-induced relaxation; (2) membrane potential; and (3) ion flux measurement. Useful information about pump activity has been generated using these techniques.

\section{Potassium-Induced Relaxation}

Vascular smooth muscle, made to contract in response to norepinephrine in a potassium-free solution, relaxes when potassium is returned to the bathing solution (Fig. 12). The magnitude of this relaxation is a functional measure of the electrogenic pumping of sodium and potassium by sodium-potassium ATPase. During the incubation in potassium-free solution, the activity of

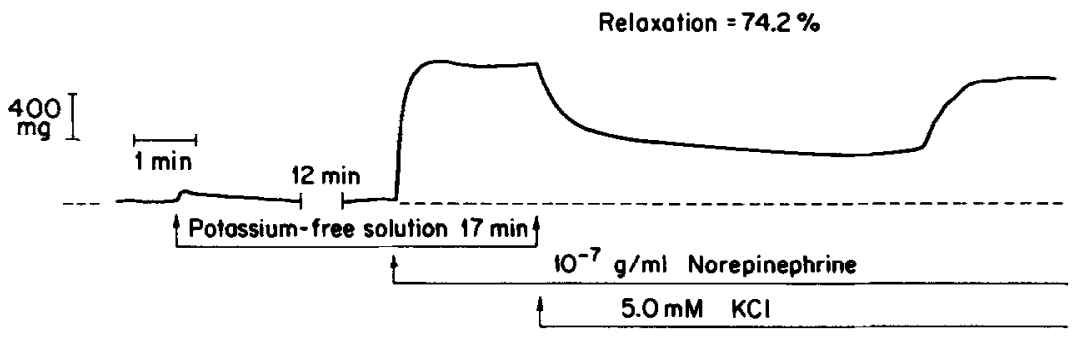

Fig. 12. Potassium-induced relaxation of vascular smooth muscle. A helical strip of rat tail artery (previously denervated by acute treatment with 6-hydroxydopamine) was made to contract by treatment with $10^{-7} \mathrm{~g} / \mathrm{ml}$ norepinephrine in potassium-free solution. Two minutes later, $5 \mathrm{mM} \mathrm{KCl}$ was added, and a decrease in tension was observed. After a few minutes, an abrupt redevelopment of tension occurred. The relaxation in response to potessium is due to the electrogenic pumping of sodium and potassium by sodium-potassium ATPase. 
the electrogenic pump is reduced leading to an accumulation of sodium intracellularly. When potassium is readmitted to the bath, the sodium pump is hyperactive because of the high intracellular concentration of sodium. Since the pump is electrogenic, membrane hyperpolarization occurs, and this event decreases membrane excitability and causes relaxation. Once the pump reduces the intracellular concentration toward normal, its activity decreases and the membrane potential returns to normal. The presence of norepinephrine then causes excitation of the cell and an abrupt increase in contractile tension is observed. The amplitude of potassium-induced relaxation is altered by experimental conditions that are known to affect the activity of sodiumpotassium ATPase: (1) sodium concentration; ${ }^{82-84}$ (2) potassium concentration; ${ }^{82-86}$ (3) magnesium concentration; $; 2$ (4) ouabain; ${ }^{66,82-88}$ (5) temperature, ${ }^{82,89}$ and (6) monovalent ion specificity. ${ }^{90.91}$

\section{Transmembrane Electrical Potential}

Many observations about the electrogenic transport of sodium and potassium have been made using electrophysiologic techniques. ${ }^{92,93}$
Inhibition of pump activity by low temperature, potassium-free solution, and ouabain causes depolarization due to a reduced net rate of transfer of positive charge from the cells. ${ }^{94,95}$ Readmission of potassium after prolonged exposure to potassium-free solution results in a rapid membrane hyperpolarization, which is blocked by treatment with ouabain (Fig. 13). The magnitude of the hyperpolarization is greater than the equilibrium potential for potassium, suggesting electrogenic transport.

\section{Ion Flux Measurement}

Sodium pump activity in isolated vascular smooth muscle has been investigated by analysis of ouabain-sensitive tissue uptake of radioactive potassium and efflux of radioactive sodium. ${ }^{67}$ The ouabain-sensitive uptake of rubidium has also been used as an estimate of pump activity in vascular smooth muscle. ${ }^{97}$ Jones and cowork$\mathrm{ers}^{67,97}$ have observed that the extracellular potassium concentration regulates both potassium uptake and sodium efflux, and that the half-concentration saturation of this regulatory effect is $2.5 \mathrm{~m} M$ potassium (see Fig. 14). Calculation of the ratio of sodium efflux to potassium

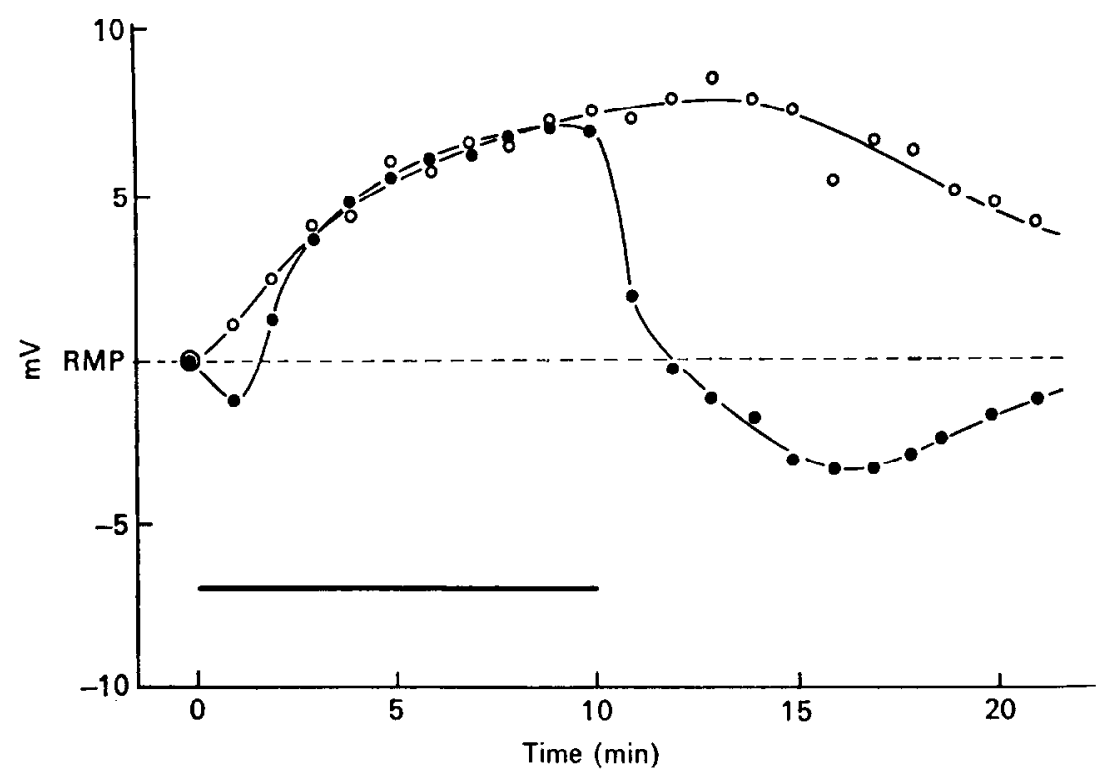

Fig. 13. Effect of potassium-free solution and ouabain on the membrane potential. The membrane potential of vascular smooth muscie cells of the rabbit main pulmonary artery were measured using conventional microelectrode techniques. Exposure to potassium-free solution (indicated by the horizontal unbroken line) for 10 min depolarized the cell, after inducing a transient hyperpolarization. Readmission of potassium to the bathing medium hyperpolarized the cell (solid circles). The membrane potential returns to its resting value within 15 min after readmitting potassium. Treatment with ouabain $12 \times 10^{-6}$ $M$ ) depolarized the membrane and blocked the hyperpolarizing effect of potassium readmission (open circles). The changes in membrane potential in $\mathrm{mV}$ are indicated by a "+" sign for depolarization and by a "-" sign for hyperpolarization. (Aeproduced by permission of Journal of Physiology (London). ${ }^{\text {A }}$ ) 


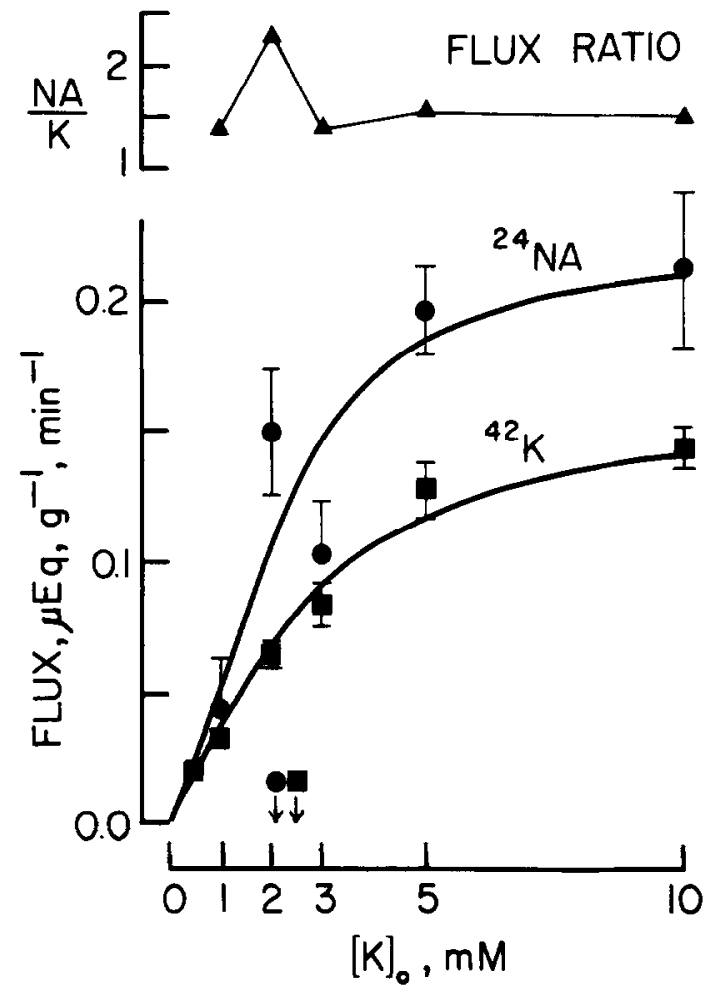

Fig. 14. Ouabain-sensitive ion fluxes in vascular smooth muscle. Ouabain-sensitive $\left(10^{-4} M\right)$ radioactive sodium efflux (circles) and radioactive potassium influx (squares) into rabbit carotid artery at various extracellular concentrations of potassium were measured. The ratio of sodium to potassium flux is shown at the top (triangles). The arrows indicate the concentretion of extracellular potassium required for half-saturation. (Reproduced by permission of the American Physiological Society. ${ }^{67}$ )

influx at each extracellular concentration of potassium yielded a ratio of three sodium ions to two potassium ions, substantiating the electrogenic character of the pump.

\section{Action Potential}

Most studies of action potentials in vascular smooth muscle have been performed on either the portal mesenteric vein or on the in situ terminal vascular bed. ${ }^{61}$ There is a close temporal relationship between the action potentials and the phasic contractile responses in these preparations. ${ }^{98}$ Although the action potentials are primitive and highly variable, interventions such as changes in electrolytes and neurohumoral agents in the environment initiate parallel changes in the mechanical responses. ${ }^{61,98}$ The propagation of action potentials occurs from cell-to-cell via low resistance tight junctions between the cells. ${ }^{2}$
The initiation of contraction without action potentials is a common observation in vascular smooth muscle. Electrophysiologic studies of the pulmonary artery, ${ }^{99}$ carotid artery, ${ }^{100}$ tail artery, ${ }^{101}$ and other small arteries have indicated that action potentials are not associated with the contractile response. In some studies, the contractile response occurred without a change in resting membrane potential, ${ }^{100}$ whereas in other studies, the contraction in response to a vasoactive agonist was accompanied by a graded depolarization of the membrane. ${ }^{101}$ Thus, it is clear that there are two different types of activation mechanisms in vascular smooth muscle: (1) a type in which membrane excitation is coupled to the generation of action potentials, and (2) a type in which membrane excitation occurs without action potentials. In the latter case, the membrane excitation may be accompanied by a graded depolarization, but it is not evident if this is related to the contractile response, since increases in membrane permeability to monovalent ions also occur under these conditions. Additionally, contraction and relaxation in response to specific agonists can occur in vascular smooth muscle placed in a depolarizing solution of potassium, which clamps the membrane potential. $^{98}$

\section{EXCITATION-CONTRACTION COUPLING}

Excitation-contraction coupling is the cellular process by which the excitatory events of the plasma membrane are linked to the interaction of the contractile proteins. Extensive evidence indicates that this coupling is the result of an increase in the cytoplasmic concentration of ionized calcium. When vascular smooth muscle is at rest, the intracellular concentration of ionized calcium is below $10^{-7} \mathrm{M}^{12.102,103} \mathrm{Maxi-}$ mum contraction occurs at $10^{-5} M$; relaxation occurs whenever the intracellular calcium concentration decreases over the range of $10^{-5}$ $M$ to $10^{-7} M$. The concentration of activator calcium is determined by the sum of the net amounts delivered and sequestered by the membrane systems already described. From a functional point of view, there are four pools of calcium regulated by the three membrane systems: (1) an extracellular pool regulated by the permeability of the plasma membrane; (2) a cellular membrane or vesicular source; (3) a mitochondrial source; and (4) a sarcoplasmic 


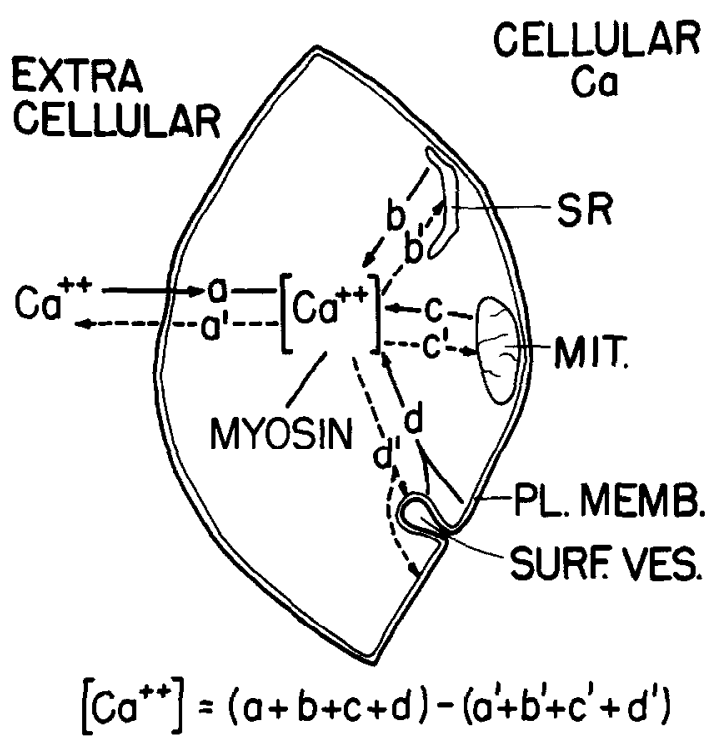

Fig. 15. Delivery and sequestration of calcium in excitation-contraction coupling. The concentration of activator calcium in the sarcoplasm is determined by the sum of the net amounts delivered and sequestered from four sources: (1) extracellular space; (2) sarcoplasmic reticulum (SA); (3) mitochondria (MIT); and (4) plasma membrane or surface vesicles. (Reproduced by permission of John Wiley \& Sons. ${ }^{201}$ )

reticular pool (Fig. 15). The contribution of activator calcium from each of these sources depends not only on the relative size of these pools but also on the mode of stimulation. Two major approaches have furnished evidence about the source of activator calcium in vascular smooth muscle: (1) cell fractionation studies and (2) studies employing agents that alter transmembrane movement of calcium.

\section{Cell Fractionation Studies}

Many investigators, using a variety of vascular tissues, have isolated subcellular fragments that are capable of actively sequestering calcium. ${ }^{75,104-114}$ The majority of these studies have used differential centrifugation of smooth muscle homogenates to isolate subcellular fractions that have been proposed to be potential sinks and sources of activator calcium. Mitochondria are isolated by sedimentation between 9500 and $15,000 \mathrm{~g}$ and a microsomal fraction is obtained by centrifugation at $40,000-150,000 \mathrm{~g}$. Purer fractions have been obtained with the aid of sucrose density gradients; ${ }^{114}$ and extraction of the microsomes in high ionic strength has been used to eliminate contamination by contractile proteins. ${ }^{75}$ Morphological studies and determi- nation of specific enzyme activities suggest that the crude microsomal fractions isolated by these methods contain membrane fragments of sarcoplasmic reticulum and surface membrane, whereas the mitochondrial fraction consists of predominantly intact mitochondria.

The ability of subcellular fractions of smooth muscle to actively sequester calcium is usually demonstrated by measuring the amount of radioactive calcium associated with membranes separated by filtration techniques. When calcium accumulation is performed in reaction mixtures containing the organic anion, oxalate, large amounts of calcium oxalate precipitates are formed within the subcellular structures. ${ }^{115}$ In the absence of agents that precipitate calcium, intravesicular or intramitochondrial precipitation of calcium salts does not occur. In these experimental situations, the maximal levels of calcium accumulation are much lower and a steady state is readily achieved.

The requirements for calcium uptake by microsomal fractions from vascular smooth muscle appear to be similar to those for skeletal and cardiac muscle with both ATP and magnesium ion being required for optimal activity. ${ }^{108,111.113}$ Substitution of $\Lambda T P$ with adenosine diphosphate (ADP) or other nucleoside triphosphates (GTP, UTP, ITP, CTP) fails to sustain microsomal calcium uptake. ${ }^{110,113}$ Microsomal calcium sequestration has also been shown to exhibit temperature and $\mathrm{pH}$ dependence. Calcium uptake is higher at $37^{\circ} \mathrm{C}$ than at $0^{\circ} \mathrm{C}$ and intermediate temperatures; optimal $\mathrm{pH}$ values of 7.4 and 7.8 have been reported. ${ }^{110,113}$

Calcium uptake by mitochondria isolated from vascular smooth muscle is not characterized as well as microsomal calcium sequestration. The uptake of calcium by the mitochondrial fraction is ATP and magnesium dependent, and it is usually observed to be somewhat greater than that in the microsomal fraction. ${ }^{75,109}$ Many studies have shown that mitochondrial calcium sequestration is strongly inhibited by the metabolic inhibitor, sodium azide. ${ }^{75,109,113}$ This effect is believed to be due to an inhibitory effect on mitochondrial ATPase.

In addition to accumulating calcium, microsomes and mitochondria isolated from vascular smooth muscle have been shown to release calcium after being preloaded. ${ }^{107,111,116,117}$ Baudouin et al. ${ }^{107}$ showed that half of the incorpo- 
rated calcium in microsomes was released within $1 \mathrm{~min}$. These investigators also showed that the addition of ATP to the medium increased the rate of release. In contrast, Shibata and Hollander $^{111}$ and Zelck et al. ${ }^{116.117}$ have shown that microsomes of vascular smooth muscle released approximately $20 \%$ of the calcium accumulated, and it was not dependent on the presence of ATP. Studies on microsomes of skeletal muscle have shown that calcium release is dependent on the presence of ADP and inorganic phosphate. ${ }^{118,119}$ This release is accompanied by the formation of ATP and is clearly demonstrated to be a reversal of the calcium pump.

\section{Studies Employing Agents That Alter Transmembrane Movement of Calcium}

The use of agents that effectively decrease transmembrane calcium movement has been a useful tool for studying the source of activator calcium in vascular smooth muscle. In general, selective suppression of calcium activation mechanisms by these agents has identified two potential sinks of calcium in vascular smooth muscle: (1) an extracellular and/or superficially bound fraction and (2) a more firmly bound and/or intracellular source.

The basis for experiments utilizing calcium entry blockers is that depolarizing concentrations of potassium and norepinephrine, epinephrine, angiotensin II, and histamine differ in the way in which they mobilize calcium to elicit contraction of vascular smooth muscle. Contractile responses induced by high concentrations of potassium decline rapidly in calcium-free medium, whereas those to norepinephrine, angiotensin II, epinephrine, and histamine persist with less reduction. ${ }^{65,120-124}$ Similarly, the addition of calcium-chelating agents (EGTA) to calcium-free medium abolishes responses to potassium, but those to norepinephrine decline slowly. ${ }^{122,123}$ Vascular smooth muscle incubated in a calcium-free potassium-depolarizing solution can be made to contract by the addition of small concentrations of calcium. These contractions are proportional to the calcium concentration and are reversible. Epinephrine can also induce contraction of vascular smooth muscle in a calcium-free, potassium-depolarizing solution, but these responses are only about one-third of the contractile tension developed in calcium- containing medium. ${ }^{125}$ Godfraind and Kaba ${ }^{125,126}$ showed that cinnarizine inhibits the contractile response to calcium of depolarized muscle, whereas it had no effect on epinephrine-induced contraction of mesenteric artery in calcium-free depolarizing solution. SKF-525A has been shown to block potassium-induced contractions of rabbit aorta ${ }^{127}$ and verapamil antagonizes the calcium-induced contractions of depolarized rabbit main pulmonary artery. ${ }^{99}$ Responses of these vessels to norepinephrine were inhibited only after long exposure to high concentrations of the calcium entry blockers. Similarly, lanthanum has a greater inhibitory effect on potassium-induced contractions of rabbit aortic smooth muscle than on responses elicited by norepinephrine. ${ }^{124,128}$ These observations suggest that potassium initiates contractions by promoting the movement of extracellular and/or superficially bound calcium to the contractile elements, but does not directly interfere with mobilization of calcium by norepinephrine from a separate morc firmly bound source. The effects of SKF-525A and lanthanum on responses to histamine and angiotensin II indicate that these stimulants utilize superficial and firmly bound calcium to differing extents in producing contraction of vascular smooth muscle. ${ }^{127,128}$ Both agents appear to activate contraction by mobilization of intracellular calcium, but histamine also appears to mobilize calcium from the superficially bound sources.

Van Breemen et al. ${ }^{124,129,130}$ have demonstrated that lanthanum blocks the passage of radioactive calcium across the cell membrane of vascular smooth muscle, while displacing superficially bound and extracellular calcium. By measuring the amount of radioactive calcium remaining in vascular strips after lanthanum treatment, these investigators have shown that increases in tension produced by potassium are paralleled by an elevation in intracellular calcium content. Norepinephrine, which also causes an increase in tension, produced no increase in intracellular calcium concentration. These results, again, indicate that contraction induced by potassium is dependent on extracellular sources of calcium whereas norepinephrine-induced contracture is dependent on intracellular pools of calcium.

These gencralizations about the mechanisms of contraction in response to potassium and nore- 
pinephrine are by no means absolute. For instance, recent observations by van Breemen and Siegel ${ }^{131}$ suggest that norepinephrineinduced contractions in dog coronary arteries are determined only by the influx of extracellular calcium across the cell membrane. Apparently, this artery does not contain an intracellular pool of calcium that is sensitive to the alpha-adrenergic agonist. Allen and coworkers ${ }^{132,133}$ have described similar evidence for an extracellular calcium source in dog basilar artery contracted with phenylephrine or serotonin. In arteries such as these, the membrane channels opened by norepinephrine appear to differ from those opened by potassium, since contractions produced by potassium are 10 times more sensitive to the calcium entry blockers, D-600 and SKF$525 \mathrm{~A}$, than those produced by norepinephrine. ${ }^{131}$

Recent studies in myocardial tissue have formed the basis for a model whereby the glycocalyx (a coating external to the unil membrane) participates in the control of transmembrane ionic exchange. ${ }^{134}$ The glycocalyx is composed of two layers: (1) an inner, less dense component (20 nm thick) and (2) an outer, slightly more dense component ( $30 \mathrm{~nm}$ thick). The inner coat is often referred to as the surface coat and the outer layer as the external lamina. The glycoca-

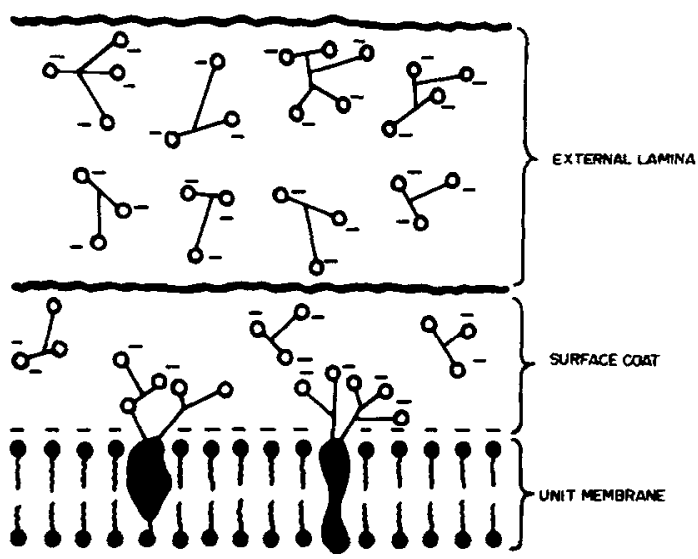

Fig. 16. Schematic representation of the unit membrane and glycocalyx. Closed circles represent hydrophilic polar heads of lipid molecules at either side of the unit membrane. The irregular structures within the unit membrane are integral proteins with negatively charged oligosaccharide chains extending into the surface coat of the glycocalyx. Other negatively charged oligosaccharide chains are present in the external lamina. The negatively cherged layer at the unit membrane surface coat interface is due in part to phospholipids. (Reproduced by permission of American Journal of Physiology. ${ }^{134}$ ) lyx has a high concentration of negatively charged sites of which sialic acid residues are a large component. These residues are terminal groups in the oligosaccharide portions of the glycoproteins and glycolipids composing the glycocalyx. The sialic acid residues of the inner surface coat are derived from integral proteins embedded in the lipid bilayer of the cell membrane (see Fig. 16). Treatment of myocardial tissue with neuraminidase, which selectively removes sialic acid residues, increases the uptake and washout of radioactive calcium approximately fivefold. Additionally, following neuraminidase treatment, lanthanum ion, which is normally restricted to the extracellular space, enters the cell and displaces more than $80 \%$ of the exchangeable calcium. These investigators proposed that the glycocalyx may be necessary for the prevention of uncontrolled entry of activator calcium into the cell. In vascular smooth muscle, contractile responses to norepinephrine or methoxamine are potentiated following treatment with neuraminidase (Fig. 17). The mechanism of this potentiation is unclear but may be

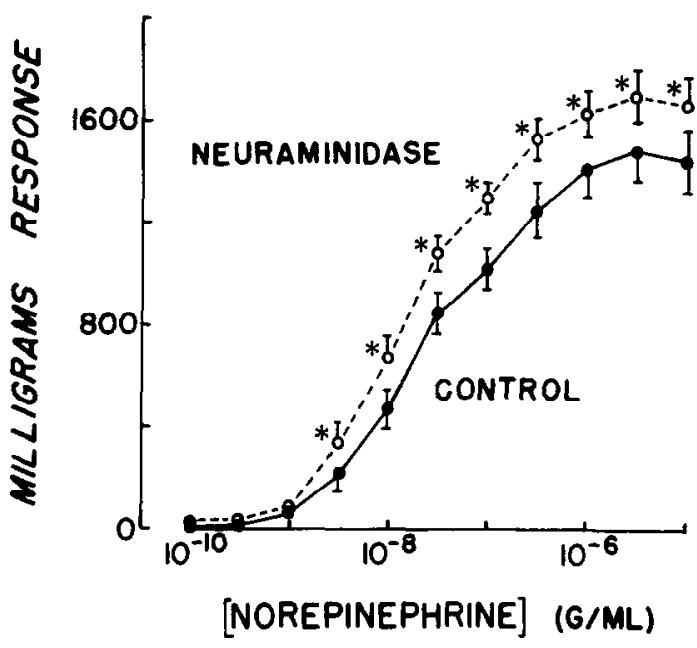

Fig. 17. Neuraminidase treatment and contractile responses to norepinephrine. Helical strips of rat tail artery were made to contract in response to the cumulative addition of norepinephrine before and after treatment with neuraminidase $10.2 \mathrm{U} / \mathrm{ml}$ in calcium-free physiologic salt solution for $60 \mathrm{~min}$ ). Following treatment with neuraminidese, contractile responses to all concentrations of norepinephrine were greater than control responses. The asterisks indicate a statistically significant difference between neuraminidase-treated strips and control strips $(p<0.05)$. The values indicate the mean \pm standard error of the mean for 5 rats (from Aice and Webb, unpublished observations, by permission.) 
related to a mechanism similar to that proposed for myocardial cells.

Sodium ions may play an important role in cell membrane transfer of calcium ions (sodiumcalcium exchange). ${ }^{135}$ Replacement of external sodium with lithium, choline, or sucrose causes reversible contractions of vascular smooth muscle. ${ }^{136-139}$ Reuter et al. ${ }^{138}$ have observed that these contractions are associated with a net gain of calcium by the tissue. The mechanism of this exchange process is believed to be a countertransport "carrier" process whereby one calcium ion is extruded and three sodium ions are accumulated by the cell. The electrochemical gradient for sodium ion is the driving force for maintenance of intracellular calcium in this model.

\section{CYCLIC NUCLEOTIDES AND THE CONTROL OF INTRACELLULAR CALCIUM}

Current observations suggest that the cyclic nucleotides may be intimately involved in the molecular events that link contraction and relaxation to the release and uptake of activator calcium by subcellular fractions. In general it is accepted that cyclic adenosine $3^{\prime}, 5^{\prime}$-monophosphate (cyclic AMP) functions in the events that lead to relaxation of smooth muscle, whereas cyclic guanosine $3^{\prime}, 5^{\prime}$-monophosphate (cyclic GMP) may participate in both the regulation of contraction and relaxation. ${ }^{140}$

\section{Cyclic AMP}

Several observations indicate that the vasodilator effect of beta-adrenergic agonists, as well as phosphodiesterase inhibitors, is mediated by cyclic AMP. Beta-adrenergic stimulants induce relaxation of vascular smooth muscle and they also cause an elevation in cyclic AMP levels. ${ }^{104,105,141-146}$ Studies by Andersson ${ }^{104}$ and Collins and Sutter ${ }^{141}$ have demonstrated a temporal and quantitative correlation between the elevation of cyclic AMP levels and the relaxing effect of isoproterenol (Fig. 18). The generation of cyclic AMP, induced by isoproterenol, can be reduced by beta-adrenergic blocking agents. ${ }^{147}$ Some investigators have reported that beta-adrenergic stimulants can also activate adenylate cyclase activity from vascular smooth muscle in cell-free systems. ${ }^{148,149}$ However, early work on homogenates of rabbit and dog arteries indicated that adenylate cyclase activity was not

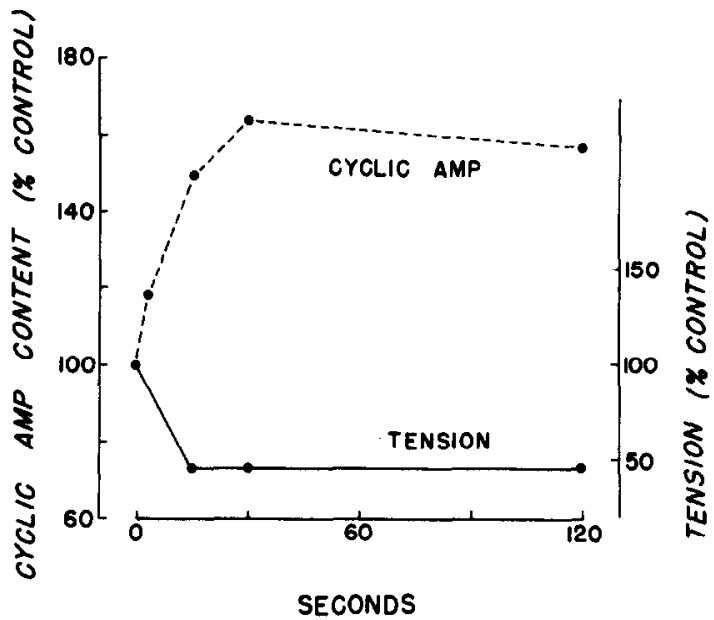

Fig. 18. Temporal relationship between cyclic AMP content and relaxation induced by isoproterenol. Rabbit anterior mesenteric-portal veins were contracted by addition of $30 \mathrm{mM} \mathrm{KCl}$ in the presence of $10^{-6} \mathrm{M}$ phentolamine. Relaxation was induced by addition of $5 \times 10^{-6} M$ isoproterenol. There was a temporal correlation between the elevation in cyclic AMP levels and the relaxing effect of isoproterenol. Each point represents the mean obtained from 4 veins. (Aeproduced by permission of Canadian Journal of Physiology and Pharmacology. ${ }^{141}$ )

activated by beta-adrenergic agonists..$^{142,150,151}$ Triner et al. ${ }^{142}$ and Namm and Leader ${ }^{152}$ suggest that homogenization of the tissue may destroy hormonal sensitivity or produce endogenous inhibitors of adenylate cyclase and therefore account for these inconsistencies. Relaxation in response to beta-adrenergic agonists has been shown to be potentiated by agents that inhibit phosphodiesterase and there is an increase in the level of cyclic AMP. ${ }^{142}$ Cyclic AMP itself or its dibutytyl derivative will produce vascular relaxation. ${ }^{104,142,147,153} 156$

Many investigators have examined the possibility that cyclic AMP mediates relaxation through the regulation of intracellular calcium. ${ }^{104.105 .147,157-161}$ Incubation of vascular smooth muscle microsomes with cyclic AMP enhances energy-dependent calcium sequestration. ${ }^{104,105,147,157-161}$ Studies on nonvascular smooth muscle $e^{104,105,147,162-169}$ and striated muscle $^{170-179}$ have yielded similar results. Calcium uptake by vascular smooth muscle microsomes has been reported to be stimulated $3 \%-49 \%$ by cyclic AMP. These responses are concentrationdependent with approximately 5-10 $\mu M$ cyclic AMP yielding the maximal response. It therefore appears that cyclic AMP may mediate 
relaxation by increasing calcium sequestration by the microsomes.

Little information is available about the mechanism by which cyclic AMP increases calcium sequestration in vascular smooth muscle, but it may be similar in nature to that which has been proposed for the heart (Fig. 19). It is now well accepted that cyclic AMP exerts its effect through the activation of cyclic-AMPdependent protein kinase. ${ }^{180,181}$ Cyclic AMP activates the enzyme by combining with the regulatory subunit, thereby causing its dissociation from the catalytic subunit of the enzyme (Fig. 19). The activated enzyme then catalyzes the transfer of the gamma-phosphate of ATP to protein substrates that participate in calcium transport.

Few studies have been performed in vascular smooth muscle that attempt to link the role of cyclic-AMP-dependent protein kinase phosphorylation with calcium metabolism. Alexander et al. ${ }^{182}$ found that microsomes prepared from the intimal-medial layers of rabbit aorta contained intrinsic protein kinase activity. This enzyme phosphorylated both endogenous and exogenous (histone) substrates. In the presence of cyclic AMP, the kinase activity was stimulated twofold. These microsomes were also shown to exhibit calcium uptake activity, and cyclic AMP increased the activity by $13 \%$. Bhalla et al. ${ }^{159}$ have observed that cyclic-AMP-dependent protein kinase augmented the phosphorylation of serine residues in an aortic microsomal protein component with a molecular weight of about 44,000 daltons. Intrinsic phosphoprotein phosphatase cleaved the labeled phosphate from the cyclic AMP-stimulated microsomes. Aortic microsomes phosphorylated in the presence of cyclic AMP or cyclic AMP plus protein kinase exhibited enhanced calcium uptake. Fitzpatrick and Szentivanyi ${ }^{161}$ have also observed that cyclic AMP plus protein kinase augments calcium transport in rabbit aortic microsomes. These studies suggest that membrane phosphorylation-
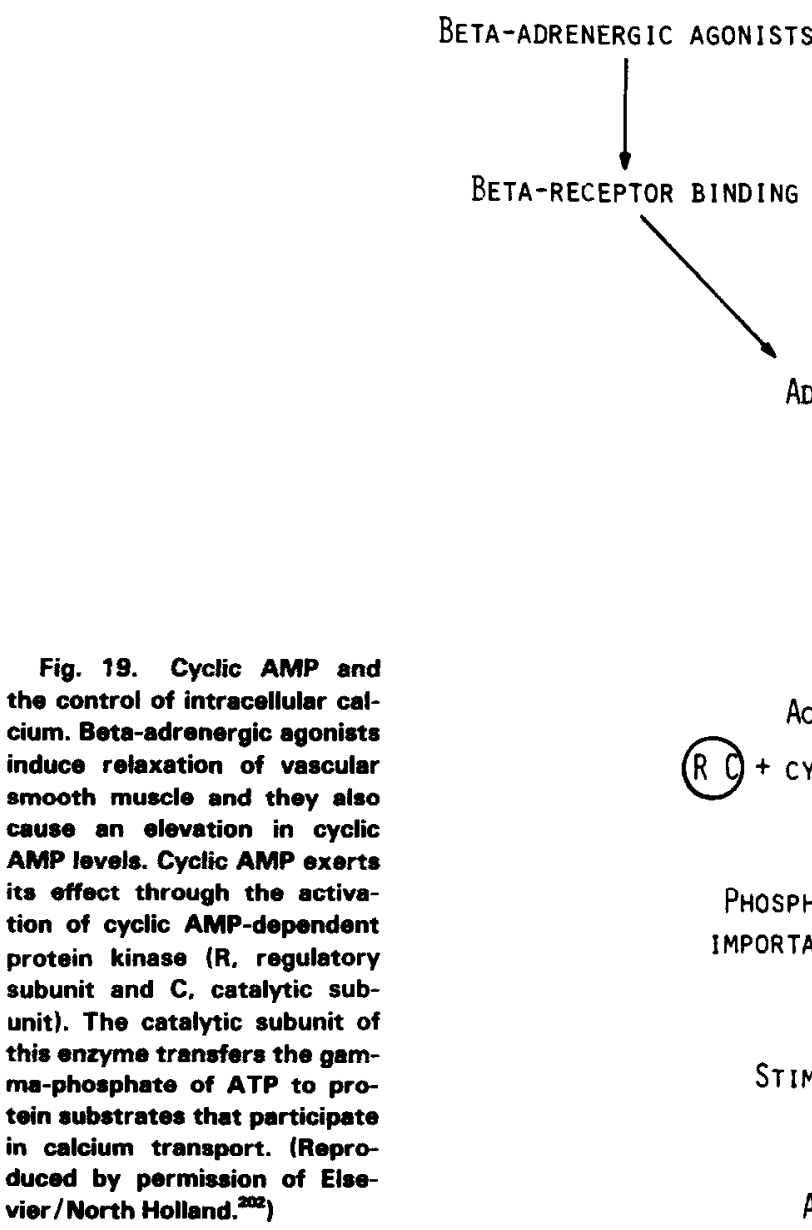

OTHER ADENYLATE

CYCLASE ACTIVATORS

ADENYLATE CYCLASE ACTIVATION

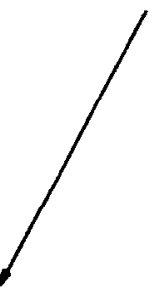

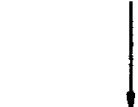

INCREASED CYCLIC AMP

MP and

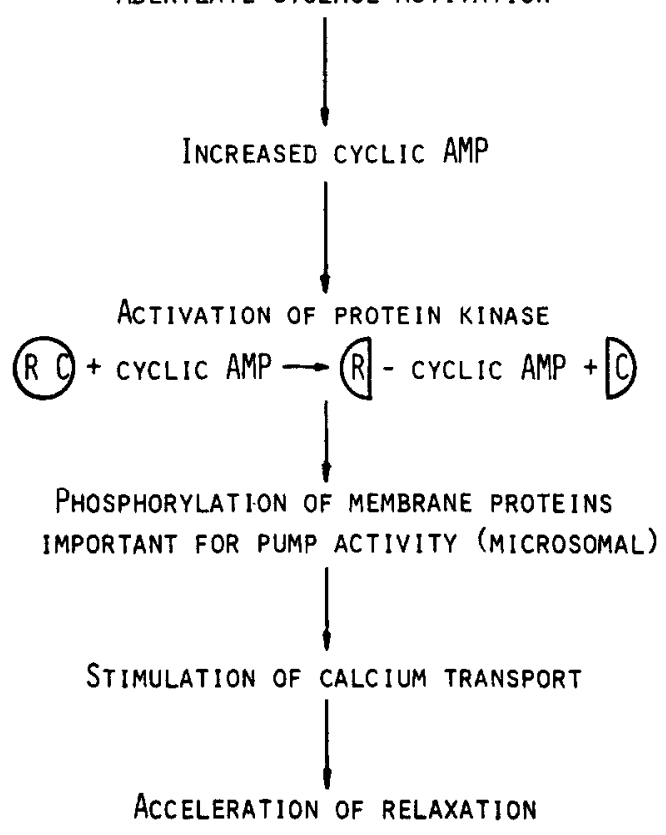


dephosphorylation may play a role in regulating calcium translocation in vascular smooth muscle. However, some investigators ${ }^{183}$ have reported that cyclic AMP does not alter microsomal calcium transport.

\section{Cyclic GMP}

The evidence implicating a role for cyclic GMP in the relaxation or contraction of vascular smooth muscle is unclear. Studies by Dunham et al. ${ }^{184}$ indicated that prostaglandin-induced contracton of bovine and canine veins was accompanied by an increase in cyclic GMP, with no consistent qualitative change in cyclic AMP concentrations. Thus, it was postulated that cyclic AMP and cyclic GMP may play opposing roles in regulating the tone of smooth muscle (Yin-Yang hypothesis). However, recent studies suggest that this hypothesis is much too simplified.

Schultz and others ${ }^{185-188}$ have observed that an increase in cyclic GMP levels in smooth muscle might be secondary to an altered calcium ion concentration. These investigators observed that segments of rat ductus deferens incubated in calcium-free medium had lower levels of cyclic GMP as compared to control. Treatment of the tissue with acetylcholine, norepinephrine, or high potassium in calcium-free medium did not increase cyclic GMP levels. However, when these agents were tested in a calcium-containing medium, cyclic GMP increased threefold. Similar studies on guinea pig intestinal smooth muscle $^{185}$ have also shown that acetylcholine, histamine, serotonin, and potassium were able to stimulate cyclic GMP levels only in the presence of calcium. In canine femoral artery, ${ }^{189}$ phenylephrine produces contraction but does not alter cyclic GMP levels, whereas carbachol and methacholine elevate cyclic GMP levels but do not cause contraction. Similarly, prostaglandins initiate contraction of human umbilical arteries but have no effect on cyclic GMP levels. ${ }^{190}$

Exogenous application of cyclic GMP to vascular preparations has also yielded information that implies that cyclic GMP may not be involved in contraction. Cohen and Berkowitz ${ }^{153}$ observed that cyclic GMP applied to isolated aortic strips results in relaxation. Schultz observed that the 8-bromo derivative of cyclic GMP, but not dibutyryl cyclic GMP, inhibited agonist-induced contractions of rat aorta. ${ }^{191}$
Schultz and coworkers ${ }^{186,188}$ have proposed that cyclic GMP is involved in the relaxation of vascular smooth muscle. Vasodilators such as nitroprusside and nitroglycerin increase the level of cyclic GMP in vascular smooth muscle up to 50 -fold. ${ }^{192}$ It is obvious that the role of cyclic GMP in contraction and relaxation of vascular smooth muscle requires further investigation.

\section{ENERGY METABOLISM AND HYPOXIA}

As in most cells, the utilizable form of chemical energy in vascular smooth muscle is that derived from the cleavage of inorganic phosphate from ATP. In relation to the function of vascular smooth muscle, it is important to determine if cellular processes involved in the production of ATP act as rate-limiting factors for contraction and relaxation.

There is evidence that vascular smooth muscle contains the enzymatic machinery for the synthesis of ATP from any of the potential fuels - carbohydrates, lipids, and proteins. ${ }^{35}$ The substrate utilization pattern of these three physiologic energy sources is unclear. Glucose uptake by vascular smooth muscle has been reported to be either greater than or less than that needed to support respiration and glycolysis. ${ }^{193,194}$ Glycogen may serve as an alternative energy source during rapid transients in contractile ATP requirements, ${ }^{195}$ however, it is not depleted during prolonged exposure to substrate-free media. ${ }^{196,197}$ Fatty acids are taken up by vascular smooth muscle, and the rate at which they are oxidized suggests that they may be utilized as a steady-state energy source ${ }^{198}$ Exogenous amino acids slightly increase or maintain respiration in vascular smooth muscle. ${ }^{199}$ The rate of ATP synthesis in vascular smooth muscle is approximately $0.5-2.0 \mathrm{~mole} / \mathrm{g}$-min, which is very similar to that of skeletal muscle under resting conditions, $0.3-2.2 \mathrm{~mole} / \mathrm{g}-\mathrm{min}^{35}$

The regulation of energy metabolism in vascular smooth muscle is mainly determined by the products of ATP hydrolysis-ADP and inorganic phosphate ${ }^{35,200}$ (see Fig. 20). If excess ADP accumulates and it is hydrolyzed to $5^{\prime}$-AMP, this nucleotide will accelerate the production of glucose- $l$-phosphate. Calcium ion also has a regulatory role in that it catalyzes the action of phosphorylase kinase.

Impaired oxygen delivery to the tissues results in vascular smooth muscle relaxation and 


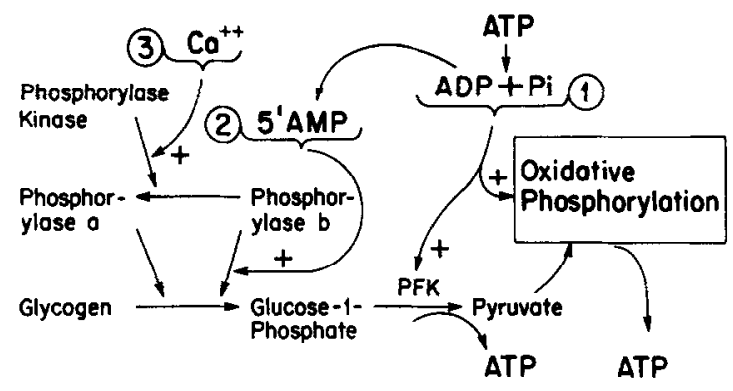

Fig. 20. Regulatory systems that stimulate ATP production and parallel increase in ATP utilization. The ADP and inorganic phosphate that result from ATP hydrolysis stimulate both glycolytic and oxidative ATP produotion (indicated by the circled "1"). The 5'-AMP that accumulates following excessive ADP production stimulates the phosphorylating action of phosphorylase b (circled " 2 "). Calcium released in excitation-contraction coupling increases the activity of phosphorylase kinase. (Reproduced by permission of John Wiley 8 Sons. ${ }^{201}$ )

conversely increased oxygen delivery results in constriction of resistance vessels. These effects are important determinants of active and passive hyperemia and may play a role in autoregulation of blood flow. It is not clear how much of these vascular smooth muscle responses are due directly to a change in the energy source or alternately to a change in the concentration of vasodilation tissue metabolites. Early observations ${ }^{203}$ indicated that the magnitude of contraction of smooth muscle of the rabbit aorta was a function of the $\mathrm{p}_{\mathrm{O}_{2}}$ over a physiologic range (see Fig. 21). This relation was thought to support the possibility that contraction of vascular smooth muscle was immediately dependent on $\mathrm{p}_{\mathrm{O}_{2}}$ for its energy supply and that this constituted a mechanism for active and reactive hyperemia. Subsequently, Pittman and Duling ${ }^{204}$ presented convincing evidence against this direct effect of $\mathrm{p}_{\mathrm{O}_{2}}$ on vascular smooth muscle contraction, suggesting that the primary regulation was effected by tissue metabolites. Now in a recent study, Detar ${ }^{205}$ observed that the hypoxic depression of vascular smooth muscle contraction is eliminated by $G$. strophanthin or in a muscle bath in which lithium had been substituted for sodium (see Fig. 22). These observations indicate that this depression may result from hypoxic stimulation of the electrogenic pump and consequent membrane hyperpolarization.

\section{SUMMARY}

The goal of this survey was to review briefly the molecular mechanisms that regulate vascular smooth muscle function. Components of the machinery involved in the contraction and relaxation of vascular smooth muscle include the following.

Contractile proteins. The force generated by vascular smooth muscle is the result of thin (actin) and thick (myosin) filaments being pulled by one another so that the cell tends to shorten. The processes by which this intereaction is regulated are a matter of some debate. However, most observations indicate that the process that initiates contraction is a calcium-dependent phosphorylation of the myosin light chain.

Cellular sites for the regulation of myoplasmic calcium concentration. The final event that initiates the contractile process is an increase in the intracellular concentration of ionized calcium. Cellular sites that may contribute to the raising and lowering of ionized calcium include the following: (A) cell mem-
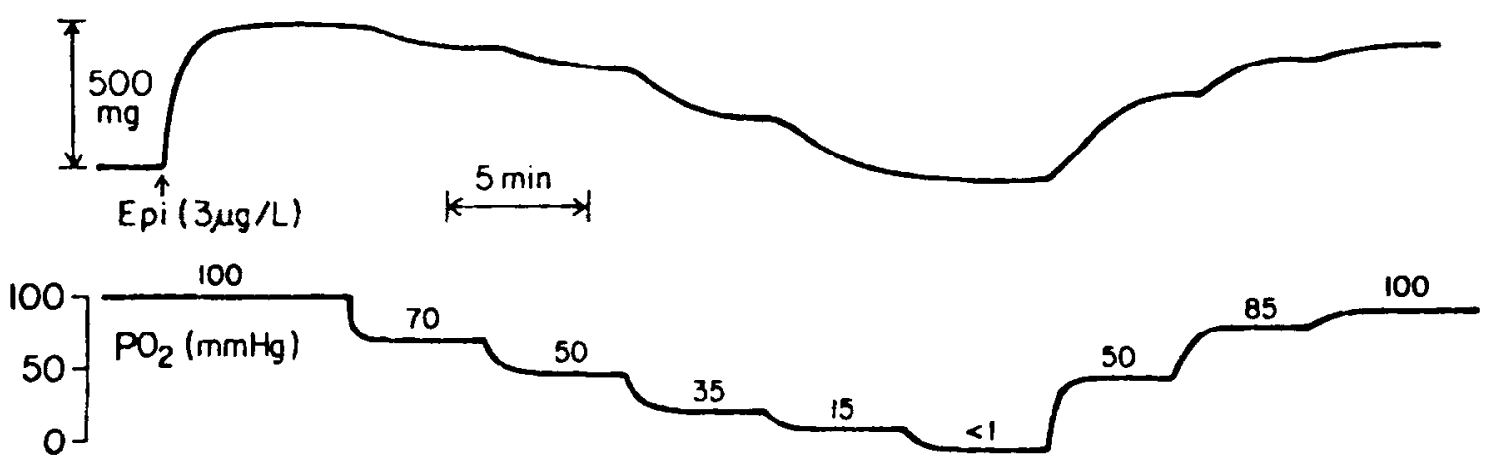

Fig. 21. Relationship of $\mathrm{p}_{2}$ to contractile tension developed by rabbit aorta strip in response to epinephrine. Specific oxygen tensions are indicated by numbers on the $\mathrm{P}_{2}$ tracing. The parallelism between smooth muscle tension and $\mathrm{p}_{\mathrm{O}_{2}}$ of the muscle bath suggest that contrectile activity is directly dependent on bath $\mathrm{P}_{\mathrm{O}_{\mathbf{z}}}$ (Reproduced by permission of American Journal of Physiology. ${ }^{200}$ ) 


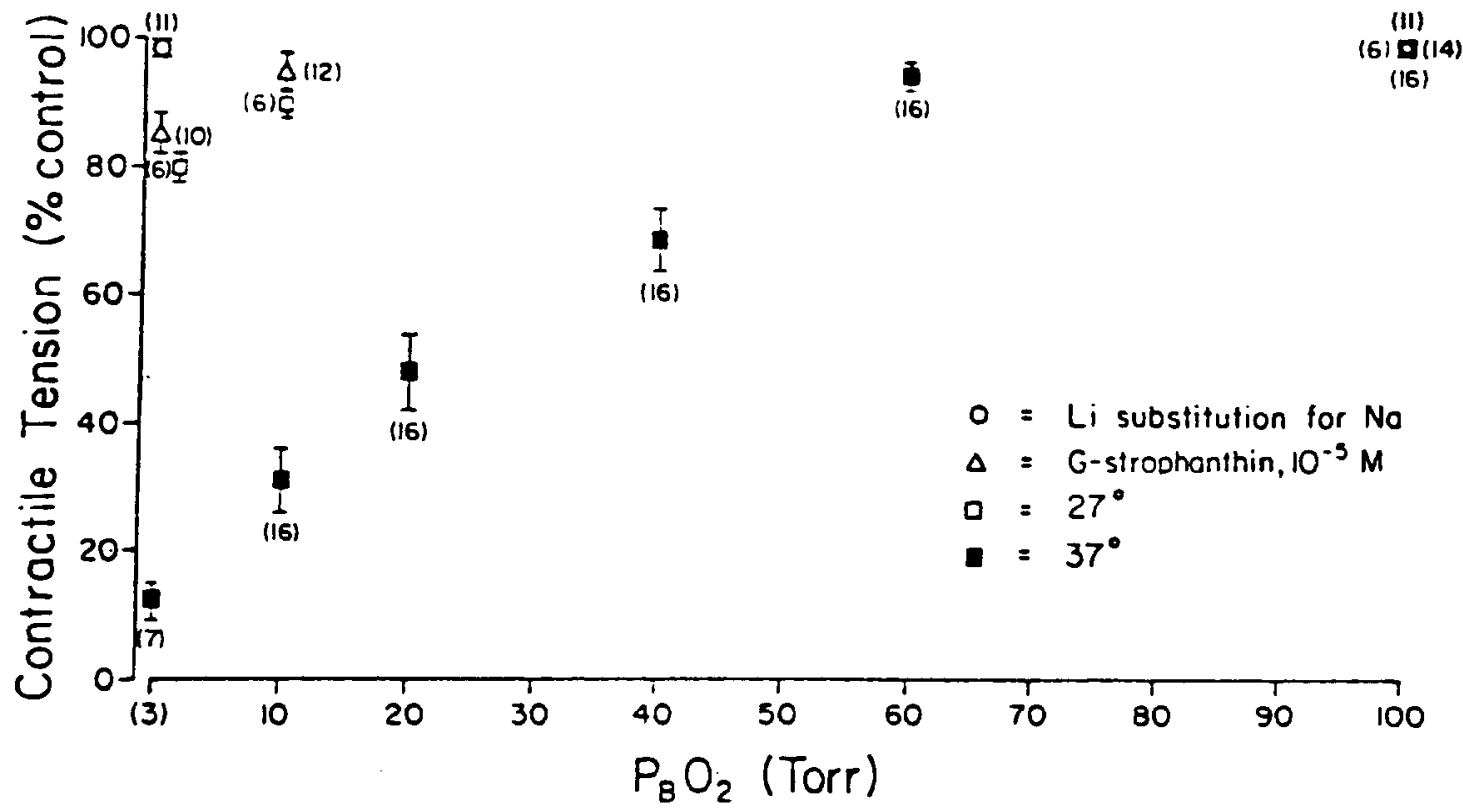

Fig. 22. Effects of G-strophanthin $\left(10^{-3} \mathrm{M}\right)$, substitution of $\mathrm{LiCl}$ for $\mathrm{NaCl}$, and reduced temperature on the relationship between $\mathrm{PO}_{2}$ and tension development in response to norepinephrine of strips from small coronary or skeletal muscle arterles of the rabbit. Numbers in parentheses indicate number of samples tested. All three test conditions inhibited the hypoxia-induced depression. Since all three conditions also inhibit the sodium-potassium APTase responsible for the electrogenic pump, these results suggest that hypoxic inhibition of contraction may reflect a stimulation of the sodiumpotessium A TPase. (Reproduced by permission of American Journal of Physiology. ${ }^{205}$ )

brane, (B) sarcoplasmic reticulum, and (C) mitochondria.

Membrane electrical events. The electrical state of the cell membrane influences contractile responses of vascular smooth muscle. Over the physiologic range, an elevation in the membrane potential has a reciprocal influence on muscle excitability. The membrane potential is the sum of the diffusion potentials and the electrogenic pump.

Excitation-contraction coupling. The excitatory events of the cell membrane (changes in membrane potential and the generation of action potentials) are coupled to the interaction of the contractile proteins by an increase in myoplasmic ionized calcium.

Cyclic nucleotides and calcium. Cyclic AMP and cyclic GMP may link contraction and relaxation to the release and uptake of activator calcium by subcellular organelles. These nucleotides also influence the level of phosphorylation of the myosin light chain.

Energy metabolism and hypoxia. The chemical energy source for cellular processes in vascular smooth muscle is ATP. Vascular tone, or maintenance of a contractile force, in this muscle is a relatively efficient process that may reflect a special noncycling link between myosin and actin. Current evidence suggests that hypoxic conditions influence vascular tone by altering the activity of the electrogenic sodium pump.

This listing of statements is by no means the final word in molecular mechanisms that govern vascular tone. Indeed, vascular smooth muscle remains to be a constant source of surprises for the interested investigator.

\section{REFERENCES}

1. Small JV, Sobieszek A: The contractile apparatus of smooth muscle. Int Rev Cytol 64:241-306, 1980

2. Somlyo AV: Ultrastructure of vascular smooth muscle, Bohr DF, Somlyo AP, Sparks HV (eds). Handbook of Physiology, sect 2, vol II, Vascular Smooth Muscle. Bethesda, American Physiological Society, 1980
3. Fay FS, Delise CM: Contraction of isolated smooth muscle cells-Structural changes. Proc Natl Acad Sci USA 70:641-645, 1973

4. Adelstein RS, Eisenberg E: Regulation and kinetics of the actin-myosin-ATP interaction. Ann Rev Biochem 49:921 956,1980 
5. Fisher BA, Bagby RM: Reorientation of myofilaments during contraction of a vertebrate smooth muscle. Am J Physiol 232:C5-C14, 1977

6. Hartshorne DJ, Gorecka A: Biochemistry of the contractile proteins of smooth muscle, in Bohr DF, Somlyo AP, Sparks HV (eds): Handbook of Physiology, sect 2, vol II, Vascular Smooth Muscle. Bethesda, American Physiological Society, 1980

7. Nonomura $Y$, Ebashi S: Calcium regulatory mechanism in vertebrate smooth muscle. Binchem Res 1:1-14, 1980

8. Sobieszek A, Small JV: Regulation of the actin-myosin interaction in vertebrate smooth muscle: Activation via a myosin light-chain kinase and the effect of tropomyosin. J Mol Biol 112:559-576, 1977

9. Barany M: ATPase activity of myosin correlated with speed of muscle shortening. J Gen Physiol 50:197-218, 1967

10. Murphy RA, Herlihy JT, Megerman J: Force-generating capacity and contractile protein content of arterial smonth muscle. J Gen Physiol 64:691-705, 1974

11. Cohen DM, Murphy RA: Differences in cellular contractile protein contents among porcine smooth muscles: Evidence for variation in the contractile system. J Gen Physiol 72:369-379, 1978

12. Filo RS, Bohr DF, Ruegg JC: Glycerinated skeletal and smooth muscle: Calcium and magnesium dependence. Science 147:1581-1583, 1965

13. Barker WC, Dayhoff MO: Evolutionary and functional relationships of homologous physiological mechanisms. Bio Sci 30:593-600, 1980

14. Ebashi $S$, Kodama A: A new protein factor promoting aggregation of tropomyosin. J Biochem 58:107-198, 1965

15. Kendrick-Jones J, Lehman W, Szent-Gyorgyi AG: Regulation in molluscan muscles. J Mol Biol 54:313-326, 1970

16. Lehman W, Szent-Gyorgyi AG: Regulation of muscular contraction, distribution of actin control and myosin control in the animal kingdom. J Gen Physiol 66:130,1975

17. Heilbrunn LV: The action of calcium on muscle protoplasm. Physiol Zool 13:88-94, 1940

18. Kamada $T$, Kinoshita $H$ : Disturbances initiated from naked surface of muscle protoplasm. Jpn J Zool 10:469-493, 1943

19. Bendall JR: Effect of the "Marsh factor" on the shortening of muscle fibre models in the presence of adenosine trophosphate. Nature 170:1058-1060, 1952

20. Szent-Gyorgyi AB: Calcium regulation of muscle contraction. Biophys J 15:707-723, 1975

21. Kendrick-Jones J: Regulatory light chains in myosins. J Mol Biol 104:747-775, 1976

22. Kendrick-Jones J, Jakes R: Regulatory light chains in myosin, in Casteels R, Godfraind T, Ruegg JC (eds): Excitation-Contraction Coupling in Smooth Muscle. Amsterdam, Elseveir/North Holland, 1977, pp 343-352

23. DiSalvo J, Gruenstein E, Silver $\mathrm{P}: \mathrm{Ca}^{2+}$ dependent phosphorylation of bovine aortic actomyosin. Proc Soc Exp Biol Med 158:410-414, 1978

24. Mrwa U, Troschka M, Gross $C$, et al: Calciumsensitivity of pig-carotid-actomyosin ATPase in relation to phosphorylation of the regulatory light chain. Eur J Biochem 103:415-419, 1980

25. Dillon PF, Aksay MO, Driska SP, et al: Myosin phosphorylation and the cross-bridge cycle in arterial smooth muscle. Multiple control systems. Science 211:495-497, 1981

26. DiSalvo J, Gruenstein E, Schmidt C: Relationships between $\mathrm{Ca}^{2+}$, myosin light chains, and ATPase in bovine aortic actomyosin: Presence of $\mathrm{Ca}^{2+}$-requiring inactivation factor. Proc Soc Exp Biol Med 162:337-341, 1979

27. Cassidy P, Hoar PE, Kerrick WGL: Exogenous calmodulin increases contraction kinetics, calcium ion sensitivity and myosin phosphorylation in smooth muscle. Fed Proc 39:2042, 1980

28. Conti MA, Adelstein RS: Phosphorylation by cyclic adenosine $3^{\prime}: 5^{\prime}$-monophosphate-dependent protein kinase regulates myosin light chain kinase. Fed Proc 39:1569-1573, 1980

29. Silver PJ, DiSalvo J: Adenosine $3^{\prime}: 5^{\prime}$-monophosphatemediated inhibition of myosin light chain phosphorylation in bovine aortic actomyosin. J Biol Chem 254:9951-9954, 1979

30. Hoar PE, Kerrick WGL, Cassidy PS: Chicken gizzard: Relation between calcium-activated phosphorylation and contraction. Science 204:503-506, 1979

31. Silver PJ, DiSalvo J: The relationship between cAMP dependent protein kinase activation and relaxation in isolated coronary arteries. Fed Proc 39:2043, 1980

32. Walus KM, Silver PJ, Jacobson ED, et al: Relaxation of coronary arteries by adenosine or its analogs is associated with activation of cAMP-dependent protein kinase. Fed Proc 39:581, 1980

33. Ebashi S: The Croonian Lecture, 1979: Regulation of muscle contraction. Proc R Soc Lond B207:259-286, 1980

34. Morgan M, Perry SV, Ottaway J: Myosin light-chain phosphatase. Biochem J 157:687-697, 1976

35. Paul RJ: Chemical energetics of vascular smooth muscle, in Bohr DF, Somlyo AP, Sparks HV (eds): Handbook of Physiology, vol II, Vascular Smooth Muscle. Bethesda, American Physiological Society, 1980

36. Ebashi S, Toyo-oka T, Nonomura Y: Gizzard troponin. J Biochem 78:859-861, 1975

37. Mikawa T, Toyo-oka T, Nonomura Y, et al: Essential factor of gizzard 'troponin' fraction. J Biochem 81:273-275, 1977

38. Marston SB, Trevett RM, Walters M: Calcium ionregulated thin filaments from vascular smooth muscle. Biochem J 185:355-365, 1980

39. Devine CE, Somlyo AV, Somlyo AP: Sarcoplasmic reticulum and excitation-contraction coupling in mammalian smooth muscle. J Cell Biol 52:690-718, 1972

40. Devine CE, Simpson FO, Bertad WS: Surface feature of smooth muscle cells from the mesenteric artery and vas deferens. J Cell Sci 8:427-443, 1971

41. Muggli R, Baumgartner HR: Pattern of membrane invaginations at the surface of smooth muscle cells of rabbit arteries. Experientia 28:1212-1214, 1972

42. Devine CE, Rayns G: Freeze-fracture studies of membrane systems in vertebrate muscle. II. Smooth muscle. J Ultrastruct Res 51:293-306, 1975

43. Lever JD, Ahmed M, Irvine G: Neuromuscular and intracellular relationships in the coronary arterioles. A morphological and quantitative study by light and electronmicroscopy. .I Anat 99:829-840, 1965

44. Irvine G, Lever JD, Ahmed J: Muscle surface specializations and the neuromuscular relationship in coronary and splanchnic arterioles. J Anat 99:409, 1965 
45. Forbes MS, Rennels L, Nelson E: Caveolar systems and sarcoplasmic reticulum in coronary smooth muscle cells of the mouse. J Ultrastruct Res 65:325-339, 1979

46. Burnstock FG: Structure of smooth muscle and its innervation, in Bulbring $\mathrm{E}$, Brading AF, Jone AW, et al (eds): Smooth Muscle. Baltimore, Williams \& Wilkins, 1970, pp 1-69.

47. Somlyo AP, Devine CE, Somlyo AV, et al: Sarcoplasmic reticulum and the temperature-dependent contraction of smooth muscle in calcium-free solutions. J Cell Biol 51:722741,1971

48. Wooton GS, Goodford PJ: An association between mitochondria and vcsicles in smooth muscle. Cell Tissue Res 161:119-132, 1975

49. Prescott L, Brightman WM: The sarcolemma of Aplysia smooth muscle in freeze-fracture preparations. Tissue Cell 8:241-258, 1976

50. Gabclla G: Cellular structures and electrophysiological behavior. Fine structure of smooth muscle. Philos Trans R Soc Lond 265:7-16, 1973

51. Forbes MS, Plantholt BA, Sperelakis N: Cytochemical staining procedures selective for sarcotubular systems of muscle: Modifications and applications. J Ultrastruct Res 60:306-327, 1977

52. Somlyo AP, Somlyo AV, Devine CE, et al: Electron microscopy and electron probe analysis of mitochondrial cation accumulation in smooth muscle. J Cell Biol 61:723742,1974

53. Somlyo AV, Somlyo AP: Strontium accumulation by sarcoplasmic reticulum and mitochondria in vascular smooth muscle. Science 174:955-958, 1971

54. Somlyo AP, Somlyo AV, Ashton FT, et al: Vertebrate smooth muscle: ultrastructure and function, in Goldman R, Pollard T, Rogenbaum J (eds): Cell Motility, vol 3 (book A). Cold Spring Harbor, NY, Cold Spring Harbor Labs, 1976, pp 165-183

55. Haack DW, Abel JH, Jaenke RS: Effects of hypoxia on the distribution of calcium in arterial smooth muscle cells of rats and swine. Cell Tissue Res 157:125-140, 1975

56. Debbas G, Hoffman L, Landon EJ, et al: Electron microscopic localization of calcium in vascular smooth muscle. Anat Rec 182:447-472, 1975

57. Jones L, Zelck V: The subcellular calcium distribution in the smooth muscle cells of the pig coronary artery. Exp Cell Res 89:352-358, 1974

58. Prosser CL, Burnstock G, Kahn J: Conduction in smooth muscle: Comparative structural properties. Am J Physiol 199:545-552, 1960

59. Peachy LD: Electron microscopic observations on the accumulation of divalent cations in intramitochondrial granules. J Cell Biol 20:95-109, 1964

60. Somlyo AP: Structural characteristics, mechanisms of contraction, innervation and proliferation of smooth muscle cells, in Wolf S, Werthesson NT (eds): The Smooth Muscle of the Artery. New York, Plenum, 1975, pp 1-80.

61. Holman ME: Electrophysiology of vascular smooth muscle. Ergebnisse Physiol 61:137-177, 1969

62. Kreye VAW: Organic nitrates, sodium nitroprusside and vasodilation, in Vanhoutte PM, Leusen I (eds): Mechanisms of Vasodilation. Basel, Karger, 1978, pp 158-164

63. Kreye VAW, Kern R, Scheich I: ${ }^{36}$ Chloride efflux from noradrenaline-stimulated rabbit aorta inhibited by sodium nitroprusside and nitroglycerine, in Casteels $\mathbf{R}$,
Godfraind T, Ruegg JC (eds): Excitation-Contraction Coupling in Smooth Muscle. Amsterdam, Elsevier/North Holland, 1977, pp 145-150

64. Harder DR, Coulsen PB: Estrogen receptors and effects of estrogen on membrane electrical properties of coronary vascular smooth muscle. J Cell Physiol 100:376382,1979

65. Axelsson J, Wahlstrom B, Johansson B, et al: Influence of the ionic environment on spontaneous electrical and mechanical activity of the rat portel vein. Circ Res 21:609-618, 1967

66. Hendrickx H, Casteels R: Electrogenic sodium pump in arterial smooth muscle cells. Pflugers Arch 346:299-306, 1974

67. Jones AW: Content and fluxes of electrolytes, in Bohr DF, Somlyo AP, Sparks HV Jr (eds): Handbook of Physiology, vol II, Vascular Smooth Muscle. Bethesda, American Physiological Society, 1980, pp 253-299

68. Schwartz A, Lindemayer GE, Allen JC: Sodiumpotassium adenosine triphosphatase. Pharmacological, physiological and biochemical aspects. Pharmacol Rev 27:3-14, 1975

69. Wallick ET, Lana LK, Schwartz A: Biochemical mechanism of the sodium pump. Annu Rev Physiol 41:397411,1979

70. Bonting SL, Simon KA, Hawkins NH: Studies on sodium-potassium-activated adenosine triphosphatase. I. Quantitative distribution in several tissues of the cat. Arch Biochem Biophysiol 95:416-423, 1961

71. Verity MA, Bevan JA: Membrane adeonsine triphosphatase activity of vascular smooth muscle. Biochem Pharmacol 18:327-338, 1969

72. Allen JC, Bukoski $\mathrm{R}$, Smith DJ, et al: $\mathrm{Na}^{+}, \mathrm{K}^{+}$ ATPase-related vascular smooth muscle heterogeneity, in Bevan JA, Maxwell RA, Godfraind T, et al (eds): Vascular Neuroeffector Mechanisms. New York, Raven, 1980, pp 327-328

73. Allen JC, Seidel CL: EGTA stimulated and ouabain inhibited ATPase of vascular smooth muscle, in Casteels $\mathbf{R}$, Godfraind T, Ruegg JC (eds): Excitation-Contraction Coupling in Smooth Muscle. Amsterdam, Elsevier/North Holland, 1977, pp 211-218

74. Eisenberg HM, Suddith RL: Cerebral vessels have the capacity to transport sodium and potassium. Science 206:1083-1085, 1979

75. Hess ML, Ford GD: Calcium accumulation by subcellular fractions from vascular smooth muscle. J Mol Cell Cardiol 6:275-282, 1974

76. Limas CJ, Cohn JN: Stimulation of vascular smooth muscle sodium, potassium-adenosinetriphosphatase by vasodilators. Circ Res 35:601-607, 1974

77. Preiss $\mathrm{R}$, Banaschak $\mathrm{H}$ : Demonstration of a $\mathrm{Mg}$ ATPase and a $\mathrm{Na}$, K-ATPase from the arteria carotis communis of the sheep. Acta Biol Med Germ 34:37-44, 1975

78. Preiss $\mathrm{R}$, Banaschak $\mathrm{H}$ : Characterization of $\mathrm{Mg}$ ATPase and $\left(\mathrm{Na}^{+}+\mathrm{K}^{+}\right)$-stimulated $\mathrm{Mg}$-ATPase in smooth muscular cells of the sheep's common carotid artery. Acta Biol Med Germ 35:453-463, 1976

79. Preiss R, Banaschak H: Na-K ATPase in excitationcontraction coupling of vascular smooth muscle from cattle. Acta Biol Med Germ 38:83-96, 1979

80. Wei JW, Janis RA, Daniel EE: Studies on subcellular 
fractions from mesenteric arteries of spontaneously hypertensive rats: Alterations in both calcium uptake and enzyme activities. Blood Vessels 13:293-308, 1980

81. Wolowyk MW, Kidwai AM, Daniel EE: Sodiumpotassium stimulated adenosinetriphosphatase of vascular smooth muscle. Can J Biochem 49:376-384, 1971

82. Webb RC, Bohr DF: Potassium-induced relaxation as an indicator of Na-K ATPase activity in vascular smooth muscle. Blood Vessels 15:193-207, 1978

83. Webb RC, Bohr DF: Mechanism of membrane stabilization by calcium in vascular smooth muscle. Am J Physiol 235:C227-C232, 1978

84. Webb RC, Bohr DF: Potassium relaxation of vascular smooth muscle from spontaneously hypertensive rats. Blood Vessels 16:71-79, 1979

85. Webb RC, Bohr DF: A comparative and regional study of potassium induced relaxation of vascular smooth muscle. J Comp Physiol 135:357-363, 1980

86. Bonaccorsi A, Hermsmeyer K, Aprigliano O, et al: Mechanism of potassium relaxation of arterial muscle. Blood Vessels 14:261-276, 1977

87. Lockette WE, Webb RC, Bohr DF: Prostaglandins and potassium relaxation in vascular smooth muscle of the rat. Circ Res 46:714-719, 1980

88. Reiner O: The role of the electrogenic sodium pump in the potassium relaxation of the rabbit ear artery. NaunynSchmiedeberg Arch Pharmacol 303:213-220, 1978

89. Toda N: Responsiveness to potassium and calcium ions of isolated cerebral arteries. Am J Physiol 227:12061211,1974

90. DeMey J, Vanhoutte PM: Dependency of monovalent alkali ions on the direct relaxant effect of acetylcholine in the canine femoral artery. Blood Vessels 17:148, 1980

91. Webb RC, Lockette WE, Vanhoutte PM, et al: Monovalent ion specificity of the electrogenic sodium pump in vascular smooth muscle. Blood Vessels 17:168, 1980

92. Anderson DK: Cell potential and the sodium-potassium pump in vascular smooth muscle. Fed Proc 35:12941297,1976

93. Johansson B, Somlyo AP: Electrophysiology and excitation-contraction coupling, in Bohr DF, Somlyo AP, Sparks HV Jr (eds): Handbook of Physiology, vol II, Vascular Smooth Muscle. Bethesda, American Physiological Society, 1980, pp 301-323.

94. Casteels R, Kitamura K, Kuriyama H, et al: The membrane properties of the smooth muscle cells of the rabbit main pulmonary artery. J Physiol Lond 271:42-61, 1977

95. Hermsmeyer K: Cellular basis for increased sensitivity of vascular smooth muscle in spontaneously hypertensive rats. Circ Res 38(Suppl II):53--57, 1976

96. Haddy F, Pamnani M, Clough D: The sodiumpotassium pump in volume expanded hypertension. Clin Exp Hypertens 1:295-336, 1978

97. Heidlage JF, Jones AW: Dependence of $\mathrm{Na}$ and $\mathrm{K}$ transport on extracellular $K$ concentration in normal and Na-loaded vascular smooth muscle. Fed Proc 37:917, 1978

98. Johansson B, Johnsson $\mathrm{O}, \Lambda$ xelsson $J$, et al: Electrical and mechanical characteristics of vascular smooth muscle response to norepinphrine and isoproterenol. Circ Res $21: 619-633,1967$

99. Haeusler $G$ : Differential effect of verapamil on excitation-contraction coupling in smooth muscle and on excita- tion-secretion coupling in adrenergic nerve terminals. J Pharmacol Exp Ther 180:672-682, 1972

100. Mekata F, Niu H: Biophysical effects of adrenaline on the smooth muscle of the rabbit common carotid artery. $J$ Gen Physiol 59:92-102, 1972

101. Hermsmeyer K: Contraction and membrane activation in several mammalian vascular muscles. Life Sci 10:223-234, 1971

102. Mrwa U, Actig I, Ruegg JC: Influences of calcium and $\mathrm{pH}$ on the tension development and ATPase activity of the arterial actomyosin contractile system. Blood Vessels 11:277-286, 1974

103. Sparrow MP, Maxwell LC, Ruegg JC, et al: Preparation and properties of a calcium ion-sensitive actomyosin from arteries. Am J Physiol 210:1366-1372, 1970

104. Andersson R: Cyclic AMP as a mediator of the relaxing action of papaverine, nitroglycerine, diazoxide and hydralazine in intestinal and vascular smooth muscle. Acta Pharmacol Toxicol 32:321-336, 1973

105. Andersson R: Role of cyclic AMP and $\mathrm{Ca}^{2+}$ in mechanical and metabolic events in isometrically contracting vascular smooth muscle. Acta Physiol Scand 87:84-95, 1975

106. Aoki K, Ikeda N, Yamashita Y, et al: Cardiovascular contraction in spontaneously hypertensive rat: $\mathrm{Ca}^{++}$ interaction of myofibrils and subcellular membrane of heart and arterial smooth muscle. Jpn Circ J 38:1115-1121, 1974

107. Baudouin-Legros $M$, Meyer P: Effects of angiotensin, catecholamines and cyclic AMP on calcium storage in aortic microsomes. Br J Pharmacol 47:377-385, 1973

108. Fitzpatrick DF, Landon E.J, Debbas G, et al: A calcium pump in vascular smooth muscle. Science 176:305306, 1972

109. Ford GD, Hess ML: Calcium-accumulating properties of subcellular fractions of bovine vascular smooth muscle. Circ Res 37:580-587, 1975

110. Moore L, Hurwitz L, Davenport GR, et al: Energydependent calcium uptake activity of microsomes from the aorta of normal and hypertensive rats. Biochim Biophys Acta 413:432-443, 1975

111. Shibata N, Hollander W: Studies on the role of arterial microsomes in the contractile function of the arteries. Exp Mol Pathol 21:1-15, 1974

112. Shibata $S$, Kuchii M, Taniquchi T: Calcium flux and binding in the aortic smooth muscle from the spontaneously hypertensive rat. Blood Vessels 12:279-289, 1975

113. Webb RC, Bhalla RC: Calcium sequestration by subcellular fractions isolated from vascular smooth muscle: Effect of cyclic nucleotides and prostaglandins. J Mol Cell Cardiol 8:145-157, 1976

114. Kwan C-Y, Belbeck L, Daniel FE: Abnormal biochemistry of vascular smooth muscle plasma membrane as an important factor in the initiation and maintenance of hypertension in rats. Blood Vessels 16:259-268, 1979

115. De Meis L, Hasselbach W, Machado RA: Characterization of calcium oxalate and calcium phosphate deposits in sarcoplasmic reticulum vesicles. J Cell Biol 62:505-509, 1974

116. Zelck V, Karnstedt V, Albrecht E: Calcium uptake and calcium release by subcellular fractions of smooth muscle. II. Kinetics of calcium uptake by microsomes and mitochondria from pig coronary artery and guinea pig ileum. Acta Biol Med Germ 34:981-986, 1975

117. Zelck V, Konva L, Albrecht E: ATP-dependent 
calcium uptake by microsomal fractions of pig coronary artery and its dependence on bradykinin and angiotensin II. Acta Biol Med Germ 32:K1-K5, 1974

118. Barlogie BW, Hasselbach W, Makinose M: Activation of calcium efflux by ADP and inorganic phosphate. FEBS Lett 12:267-270, 1971

119. Makinose M, Hasselbach W: ATP synthesis by the reverse of the sarcoplasmic calcium pump. FEBS Lett 12:271-272, 1971

120. Briggs AH: Calcium movements during potassium contracture in isolated rabbit aortic strjps. Am J Physiol 203:849-852, 1962

121. Briggs AH, Mervin S: Ion movements in isolated rabbit aortic strips. Am J Physiol 201:365-368, 1961

122. Hinke JAM: Calcium requirements of noradrenaline and high potassium ion contraction in arterial smooth muscle, in Paul WM, Daniel EE, Kay CM, et al (eds): Muscle. New York, Pergamon, 1965, pp 269-285

123. Hudgins PM, Weiss GB: Differential effects on calcium removal upon vascular smooth muscle contraction induced by norepinephrine, histamine and potassium. J Pharmacol Exp Ther 159:91-97, 1968

124. Van Breemen C, Farinas BR, Gerba D, et al: Excitation-contraction coupling in rabbit aorta studied by the lanthanum method for measuring cellular calcium influx. Circ Res 30:44-45, 1972

125. Godfraind T, Kaba A: Blockade or reversal of the contraction induced by calcium and adrenaline in depolarized arterial smooth muscle. Br J Pharmacol 36:549-560, 1969

126. Godfraind T, Kaba A: The role of calcium in the action of drugs on vascular smooth muscle. Arch Int Pharmacodyn Ther 196:35-49, 1972

127. Kalsner S, Nickerson M, Goyd GN: Selective blockade of potassium-induced contractions of aortic strips by $\beta$-diethyl-aminoethyldiphenyl-propylacetate (SKF-525A). J Pharmacol Exp Ther 174:500-508, 1970

128. Goodman RF, Weiss GB: Effects of lanthanum on ${ }^{45} \mathrm{Ca}$ movements and on contractions induced by norepinephrine, histamine and potassium in vascular smooth muscle. J Pharmacol Exp Ther 177:415-425, 1971

129. Van Breemen C: Transmembrane calcium transport. Blood Vessels 12:333-334, 1975

130. Van Breemen C, Wuytack F, Casteels R: Stimulation of ${ }^{15} \mathrm{Ca}$ efflux from smooth muscle cells by metabolic inhibition and high $\mathrm{K}$ depolarization. Pflugers Arch 359:183-186, 1975

131. Van Breemen C, Siegel B: The mechanism of $\alpha$ adrenergic activation of dog coronary artery. Circ Res 46:426-429, 1980

132. Allen GS, Banghart SB: Cerebral arteriospasm, part 9. In vitro effects of nitedipine on serotonin-, phenylephrine-, and potassium-induced contractions of canine basilar and femoral arteries. Neurosurgery 4:37-42, 1979

133. Allen GS, Gross CJ, Henderson LM, et al: Cerebral arterial spasm, part 4 . In vitro effects of temperature, serotonin analogues, large nonphysiological concentrations of serotonin and extracellular calcium and magnesium on serotonin-induced contractions of the canine basilar artery. $J$ Neurusury 44:585-593, 1976

134. Langer GA: The structure and function of the myocardial cell surface. Am J Physiol 235:H461-H468, 1978
135. Blaustein MP: Sodium ions, calcium ions, blood pressure regulation, and hypertension: A reassessment of a hypothesis. Am J Physiol 232:C165-C173, 1977

136. Blaustein MP: Sodium-calcium exchange and the regulation of cell calcium in muscle fibers. Physiologist 15:525-540, 1976

137. Hinke JAM, Wilson ML: Effects of electrolytes on contractility of artery segments in vitro. Am J Physiol 203:1161-1166, 1962

138. Reuter H, Blaustein MP, Haeusler G: $\mathrm{Na}-\mathrm{Ca}$ exchange and tension development in arterial smooth muscle. Philos Trans R Soc Lond 265:87-94, 1973

139. Sitrin MD, Bohr DF: $\mathrm{Ca}$ and $\mathrm{Na}$ interactions in vascular smooth muscle contraction. Am J Physiol 220:1124-1128, 1971

140. Kramer GL, Hardman JG: Cyclic nucleotides and blood vessel contraction, in Bohr DF, Somlyo AP, Sparks HV Jr (eds): Handbook of Physiology, vol II, The Cardiovascular System, Vascular Smooth Muscle. Bethesda, American Physiological Society, 1980, pp 179-199

141. Collins GA, Sutter MC: Quantitative aspects of cyclic AMP and relaxation in the rabbit anterior mesenteric portal vein. Can J Physiol Pharmacol 53:989-997, 1975

142. Triner L, Nahas GG, Vulliemoz Y, et al: Cyclic AMP and smooth muscle function. Ann NY Acad Sci 185:458-476, 1971

143. Gilbert $\mathrm{CH}$, Galton DJ: The presence of a hormonesensitive cyclase system in the rat aorta and its relation to lipolysis. Atherosclerosis 18:257-264, 1973

144. Ericsson E, Lundholm L: Adrenergic $\beta$-receptor activity and cyclic AMP metabolism in vascular smooth muscle; variations with age. Mech Ageing Dev 4:1-6, 1975

145. Lockwood R, Phornchirasilp S: Selective block of cardiovascular adenylate cyclase activation in vivo. J Pharm Pharmacol 29:184-186, 1977

146. Shepherd AP, Mao CC, Jacobson ED, et al: The role of cyclic AMP in mesenteric vasodilation. Microvasc Res 6:332-341, 1973

147. Andersson R, Lundholm L, Mohme-Lundholm E: Role of cyclic AMP and $\mathrm{Ca}^{++}$in mechanical and metabolic events of smooth muscle, in Betz E (ed): Vascular Smooth Muscle. Berlin, Springer-Verlag, 1972, pp 14-16

148. Amer MS: Cyclic adenosine monophosphate and hypertension in rats. Science 179:807-809, 1973

149. Volicer L, Hynie S: Effect of catecholamines and angiotensin on cyclic AMP in rat aorta and tail artery. Eur $J$ Pharmacol 15:214-220, 1971

150. Klainer LM, Chi YM, Friedberg SL, et al: Adenyl cyclase. IV. The effects of neurohormone on the formation of adenosine $3^{\prime} 5^{\prime}$-phosphate by preparations from brain and other tissues. J Biol Chem 237:1239-1243, 1964

151. Schohofer PS, Skidmore EF, Forn J, et al: Adenyl cyclase activity of rabbit aorta. J Pharm Pharmacol 23:2831, 1971

152. Namm DH, Leader JP: Occurrence and function of cyclic nucleotides in blood vessels. Blood Vessels 13:24-47, 1976

153. Cohen ML, Berkowitz BA: Decreased vascular relaxation in hypertension. J Pharmacol Exp Ther 196:396406,1976

154. Berti F, Sirtori C, Usardi MM: Cyclic 3',5'-AMP, its dibutyryl derivative and theophylline effects on the rat portal 
vein in vitro. Arch Int Pharmacodyn Ther 184:328-333, 1970

155. Rubin B, O'Keefe EH, Waugh $\mathrm{MH}$, et al: Activities in vitro of 8 -substituted derivatives of adenosine- $3^{\prime}, 5^{\prime}$-cyclic monophosphate on guinea pig tracha and rat portal vein. Proc Soc Exp Biol Med 137:1244-1248, 1971

156. Seidel CL, Schnarr RL, Sparks HV: Coronary artery cyclic AMP content during adrenergic receptor stimulation. Am J Physiol 229:265-269, 1975

157. Baudouin-Legros M, Meyer P: Effects of angiotensin, catecholamines and cyclic AMP on calcium storage in aortic microsomes. Br J Pharmacol 47:377-385, 1973

158. Webb RC, Bhalla RC: Calcium sequestration by subcellular fractions isolated from vascular smooth muscle: Effect of cyclic nucleotides and prostaglandins. J Mol Cell Cardiol 8:145-157, 1976

159. Bhalla RC, Webb RC, Singh D, et al: The role of cyclic AMP in rat aortic microsomal phosphorylation and calcium uptake. Am J Physiol 234:H508-H514, 1978

160. Bhalla RC, Webb RC, Singh D, et al: Calcium fluxes, calcium binding and cyclic AMP dependent protein kinase activity in the aorta of spontaneously hypertensive and Kyoto Wistar normotensive rats. Mol Pharmacol $14: 468-477,1978$

161. Fitzpatrick DF, Szentivanyi A: Stimulation of calcium uptake into aortic microsomes by cyclic AMP and cyclic AMP-dependent protein kinase. Naunyn-Schmiedeberg Arch Pharmacol 298:255-257, 1977

162. Andersson R: Role of cyclic AMP and $\mathrm{Ca}^{++}$in the metabolic and relaxing effects of catecholamines in intestinal smooth muscle. Acta Physiol Scand 85:312-322, 1972

163. Andersson R, Lundholm L, Mohme-Lundholm E, et al: Role of cyclic AMP and $\mathrm{Ca}^{++}$in metabolic and mechanical events in smooth muscle. Adv Cycl Nucl Res 1:213-229, 1972

164. Andersson R, Nilsson K: Cyclic AMP and calcium in relaxation in intestinal smooth muscle. Nature (New Biol) 238:119-120, 1972

165. Andersson R, Nilsson K, Wikberg J, et al: Cyclic nucleotides and the contraction of smooth muscle. Adv Cyci Nucl Res 5:491-518, 1975

166. Korenman SG, Krall JF: The role of cyclic AMP in the regulation of smooth muscle cell contraction in the uterus. Biol Reprod 16:1-17, 1977

167. D'Auriac GA, Baudouin M, Meyer P: Mechanism of action of angiotensin in smooth muscle cell. Biochemical changes following interaction of the hormone with its membrane receptor. Circ Res 30-31 (Suppl II):151-157, 1972

168. Nishikori K, Takenaka T, Meeno H: Stimulation of microsomal calcium uptake and protein phosphorylation by adenosine cyclic $3^{\prime}, 5^{\prime}$-monophosphate in rat uterus. Mol Pharmacol 13:671-678, 1977

169. Krall JF, Swensen JL, Korenman SG: Hormonal control of uterine contraction. Characterization of cyclic AMP-dependent properties in the myometrium. Biochim Biophys Acta 448:578-588, 1976

170. Kirchberger MA, Tada M: Effects of adenosine $3^{\prime}, 5^{\prime}$-monophosphate-dependent protein kinase on sarcoplasmic reticulum isolated from cardiac and slow and fast contracting skeletal muscles. J Biol Chem 251:725-729, 1976

171. Kirchberger MA, Tada M, Katz AM: Adenosine 3',5'-monophosphate-dependent protein kinase-catalyzed phosphorylation reaction and its relationship to calcium transport in cardiac sarcoplasmic reticulum. J Biol Chem 249:6166-6173, 1974

172. Kirchberger MA, Tada M, Katz AM: Mechanism of the relaxation promoting effects of epinephrine on the mammalian heart, in Klinge E (ed): Proceedings of the 6th International Congres of Pharmacology. Receptors and Cellular Pharmacology, vol. 1. New York, Pergamon, 1976, pp 193-202

173. Kirchberger MA, Tada M, Repke DI, et al: Cyclic adenosine $3^{\prime}, 5^{\prime}$-monphosphate-dependent protein kinase stimulation of calcium uptake by canine cardiac microsomes. J Mol Cell Cardiol 4:673-680, 1972

174. LaRaia PJ, Morkin E: Adenosine $3^{\prime}, 5^{\prime}$-monophosphate-dependent membrane phosphorylation: A possible mechanism for the control of microsomal calcium transport in heart muscle. Circ Res 35:298-306, 1974

175. LaRaia PJ, Morkin E: Phosphorylation-dephosphorylation of cardiac microsomes. A possible mechanism for control of calcium uptake by cyclic AMP, in Dhalla NS (ed): Recent Advances on Cardiac Structure and Metabolism, vol 4. Baltimore, University Park Press, 1974, pp 417-426

176. Morkin E, LaRaia PJ: Biochemical studies on the regulation of myocardial contractility. $\mathrm{N}$ Engl $\mathrm{J}$ Med 290:445-451, 1974

177. Schwartz A, Entman ML, Kanike K, et al: The rate of calcium uptake into sarcoplasmic reticulum of cardiac and skeletal muscle. Effects of cyclic AMP-dependent protein kinase and phosphorylase b kinase. Biochim Biophys Acta 436:57-72, 1976

178. Shinebourne E, White R: Cyclic AMP and calcium uptake of the sarcoplasmic reticulum in relation to increased rate of relaxation under the influence of catecholamines. Cardiovasc Res 4:194-200, 1970

179. Hicks MJ, Shigekawa M, Katz AM: Mechanism by which cyclic adenosine $3^{\prime}: 5^{\prime}$-monophosphate-dependent protein kinase stimulates calcium transport in cardiac sarcomplasmic reticulum. Circ Res 44:384-391, 1979

180. Kuo JF, Greengard P: Cyclic nucleotide-dependent protein kinases. IV. Widespread occurrence of adenosine $3^{\prime}-5^{\prime}$ monophosphate-dependent protein kinase in various tissues and phyla of the animal kingdom. Proc Natl Acad Sci USA 64:1349-1355, 1969

181. Langan TA: Protein kinases and protein kinase substrates. Adv Cycl Nucl Res 3:99-153, 1973

182. Alexander RW, Fontana JA, I ovenberg W: cAMP dependent protein kinase in rabbit aortic microsomes and its relation to $\mathrm{Ca}^{++}$uptake. Fed Proc 32:711, 1973 (abstr)

183. Sands H, Mascali J, Paietta E: Determination of calcium transport and phosphoprotein phosphatase activity in microsomes from respiratory and vascular smooth muscle. Biochim Biophys Acta 500:223-234, 1977

184. Dunham EW, Haddox MK, Goldberg ND: Alteration of vein cyclic $3^{\prime}: 5^{\prime}$ nucleotide concentrations during changes in contractility. Proc Natl Acad Sci USA 71:815819,1974

185. Schultz G, Hardman RG, Hurwitz L: Cyclic nucleotides and smooth muscle function, in Klinge $E$ (ed): Proceedings of the 6th International Congress of Pharmacology. Receptors and Cellular Pharmacology, vol 1. New York, Pergamon, 1976, pp 203-211.

186. Schultz G, Hardman JG, Schultz K, et al: The 
importance of calcium ions for the regulation of guanosine $3^{\prime}: 5$ '-cyclic monophosphate levels. Proc Natl Acad Sci USA 70:3889-3893, 1973

187. Schultz G, Hardman JG, Sutherland EW: Cyclic nucleotides and smooth muscle function, in Austen KF, Lichtenstein LM (eds): Asthma. New York, Academic, 1973, pp 123-138

188. Schultz G, Schultz K, Hardman JG: Effects of norepinephrine on cyclic nucleotide levels in the ductus deferens of the rat. Metabolism 24:429-437, 1975

189. Diamond J, Blisard KS: Effects of stimulant and relaxant drugs on tension and cyclic nucleotide levels in canine femoral artery. Mol Pharmacol 12:688-692, 1976

190. Clyman RI, Sandler JA, Mangaiello V, et al: Guanosine $3^{\prime}, 5^{\prime}$-monophosphate and adenosine $3^{\prime}, 5^{\prime}$-monophosphate content of human umbilical artery. Possible role in perinatal artery potency and closure. J Clin Invest 55:1020-1025, 1975

191. Schultz K-D: Effects of 8-Br-cGMP on the tonus of rat ductus deferens and aorta. Naunyn-Schmiedeberg Arch Pharmacol 297:R12, 1977

192. Bohme E, Grat H, Schultz G: Effects of sodium nitroprusside and other smooth muscle relaxants on cyclic GMP formation in smooth muscle and platelets. Adv Cycl Nucl Res 9:131-143, 1978

193. Kirk JE, Effersoe PG, Chang SP: The role of respiration and glycolysis by human and dog aortic tissue. J Gerontol 9:10-35, 1954

194. St Clair RW, Booth NH, Hopwood ML: Influence of hypertension, sex, and estrogen on metabolism of swine arteries. Am J Physiol 210:880-884, 1966

195. Namm DH: The activation of glycogen phosphorylase in arterial smooth muscle. J Pharmacol Exp Ther 178:299-310, 1971
196. Hellstrand P, Johansson B, Norberg K: Mechanical, electrical and biochemical effects of hypoxia and substrate removal on spontaneously active vascular smooth muscle. Acta Physiol Scand 100:69-83, 1977

197. Lundholm L, Mohme-Lundholm E: The carbohydrate metabolism and tone of smooth muscle. Acta Pharmacol Toxicol 16:374-388, 1960

198. Morrison ES, Scott RF, Kroms M, et al: Uptake, oxidation and esterification of free fatty acids in normal and atherosclerotic rabbit aorta. Biochem Med 11:153-164, 1974

199. Briggs FN, Chernick S, Chaikoff IL: The metabolism of arterial tissue. I. Respiration of rat thoracic aorta. J Biol Chem 179:103-111, 1949

200. Namm DH: Control of energy metabolism in vascular smooth muscle, in Bevan JA (ed): Vascular Neuroeffector Mechanisms. Basel, S. Karger, 1976, p 86

201. Bohr DF: Vascular smooth muscle, in Johnson PC (ed): Peripheral Circulation. New York, John Wiley \& Sons, 1978, pp 1343

202. Tada M, Kirchberger MA, Li H-C, et al: Interrelationships between calcium and cyclic AMP in the mammalian heart. in: Carafoli E, Clementi F, Drabikowski W, et al (eds): Calcium Transport in Contraction and Secretion. Amsterdam, Elsevier/North Holland, 1975, pp 373-381

203. Detar R, Bohr D: Oxygen and vascular smooth muscle contraction. Am J Physiol 214:241-244, 1968

204. Pittman RN, Dulung BR: Oxygen sensitivity of vascular smooth muscle. I. In vitro studies. Microvasc Res 6:202-211, 1976

205. Detar R: Mechanism of physiological hypoxiainduced depression of vascular smooth muscle contraction. Am J Physiol 238:H761-H769, 1980 